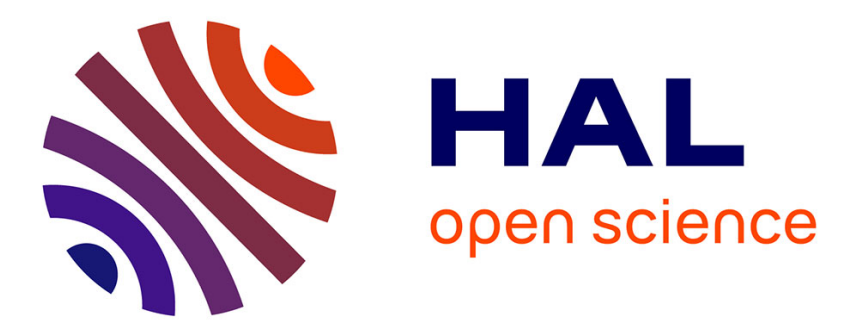

\title{
Clay clast aggregates in gouges: New textural evidence for seismic faulting
}

Sébastien Boutareaud, Anne-Marie Boullier, Muriel Andreani, Dan-Gabriel Calugaru, Pierre Beck, Sheng-Rong Song, Toshihiko Shimamoto

\section{To cite this version:}

Sébastien Boutareaud, Anne-Marie Boullier, Muriel Andreani, Dan-Gabriel Calugaru, Pierre Beck, et al. Clay clast aggregates in gouges: New textural evidence for seismic faulting. Journal of Geophysical Research : Solid Earth, 2010, 115, pp.15. 10.1029/2008JB006254 . insu-00644945

\section{HAL Id: insu-00644945 \\ https://hal-insu.archives-ouvertes.fr/insu-00644945}

Submitted on 5 Mar 2021

HAL is a multi-disciplinary open access archive for the deposit and dissemination of scientific research documents, whether they are published or not. The documents may come from teaching and research institutions in France or abroad, or from public or private research centers.
L'archive ouverte pluridisciplinaire HAL, est destinée au dépôt et à la diffusion de documents scientifiques de niveau recherche, publiés ou non, émanant des établissements d'enseignement et de recherche français ou étrangers, des laboratoires publics ou privés. 


\title{
Clay clast aggregates in gouges: New textural evidence for seismic faulting
}

\author{
Sébastien Boutareaud, ${ }^{1}$ Anne-Marie Boullier, ${ }^{2,3}$ Muriel Andréani, ${ }^{4}$ Dan-Gabriel Calugaru, ${ }^{5}$ \\ Pierre Beck, ${ }^{6}$ Sheng-Rong Song, ${ }^{3,7}$ and Toshihiko Shimamoto ${ }^{8}$ \\ Received 16 December 2008; revised 10 July 2009; accepted 28 September 2009; published 12 February 2010.
}

[1] Spherical aggregates named clay-clast aggregates (CCAs) have been reported from recent investigations on retrieved clay-bearing fault gouges from shallow depth seismogenic faults and rotary shear experiments conducted on clay-bearing gouge at seismic slip rates. The formation of CCAs appears to be related to the shearing of a smectite-rich granular material that expands and becomes fluidized. We have conducted additional high-velocity rotary shear experiments and low-velocity double-shear experiments. We demonstrate that a critical temperature depending on dynamic pressure-temperature conditions is needed for the formation of CCAs. This temperature corresponds to the phase transition of pore water from liquid to vapor or to critical, which induced gouge pore fluid expansion and therefore a thermal pressurization of the fault. A detailed examination by energy dispersive X-ray spectrometry (EDX-SEM) element mapping, SEM, and transmission electron microscopy (TEM) shows strong similar characteristics of experimental and natural CCAs with a concentric well-organized fabric of the cortex and reveals that their development may result from the combination of electrostatic and capillary forces in a critical reactive medium during the dynamic slip weakening. Accordingly, the occurrence of CCAs in natural clay-rich fault gouges constitutes new unequivocal textural evidence for shallow depth thermal pressurization and consequently for past seismic faulting.

Citation: Boutareaud, S., A.-M. Boullier, M. Andréani, D.-G. Calugaru, P. Beck, S.-R. Song, and T. Shimamoto (2010), Clay clast aggregates in gouges: New textural evidence for seismic faulting, J. Geophys. Res., 115, B02408, doi:10.1029/2008JB006254.

\section{Introduction}

[2] Fault gouge spherical clast-clay aggregates (CCAs), i.e., disjunctive monomineralic or polymineralic clasts surrounded by a cortex of concentric fine-grained aggregated material, have been found in association with carbonate-rich or smectite-rich fault rocks [Beutner and Gerbi, 2005; Warr and Cox, 2001; Boullier et al., 2009]. Smectite (montmorillonite), as an alteration product of cataclastic fault-rock primary minerals, is of particular interest because it is a common mineral found in gouges within the principal slip

\footnotetext{
${ }^{1}$ Geologisches Institut, ETH-Zentrum, Zurich, Switzerland.

${ }^{2}$ Laboratoire de Géophysique Interne et Tectonophysique, Université Joseph Fourier, CNRS, Grenoble, France.

${ }^{3}$ International Laboratory, ADEPT, France-Taiwan, CNRS, NSC, Taipei, Taiwan.

${ }^{4}$ Laboratoire des Sciences de la Terre, UMR 5570, Université Claude Bernard, Ecole Normale Supérieure de Lyon, CNRS, INSU, Villeurbanne, France.

${ }^{5}$ Laboratoire de Mathématiques, Université de Franche-Comté, Besançon, France.

${ }^{6}$ Laboratoire de Planétologie de Grenoble, Université Joseph Fourier, Grenoble, France.

${ }^{7}$ Department of Geosciences, National Taiwan University, Taipei, Taiwan.

${ }^{8}$ Department of Earth and Planetary Systems Science, Hiroshima University, Higashi-Hiroshima, Japan.
}

Copyright 2010 by the American Geophysical Union. 0148-0227/10/2008JB006254\$09.00 zones (PSZ) [Sibson, 2003] of crustal faults [Wang et al., 1980; Vrolijk and van der Pluijm, 1999]. In addition, its occurrence as mixed-layer phases has been recently found in association with active fault branches of the San Andreas fault [Solum et al., 2006], the Nojima fault [Ohtani et al., 2000; Mizoguchi et al., 2008], and the Chelungpu fault [Kuo et al., 2005]. For the Chelungpu fault, Boullier et al. [2009] have recognized the Chi-Chi earthquake PSZ on the basis of its microstructures (isotropic layer without any later veins, shear zones, or fractures), in which they have observed natural CCAs. Similar to previous authors [Tanaka et al., 2006; Kano et al., 2006], they conclude that CCAs, together with other evidence such as grain size segregation obeying Brazil nut effect and isotropic texture of the PSZ, although more than $8 \mathrm{~m}$ of displacement took place on it, are good microstructural markers for fluidization and thermal pressurization during the 1999 Chi-Chi earthquake.

[3] To understand the structure and the mechanical behavior of the PSZ during an earthquake, several authors [Mizoguchi, 2004; Mizoguchi et al., 2007b; Boutareaud, 2007; Boutareaud et al., 2008c; Brantut et al., 2008] have recently experimentally reproduced seismic slip along a fault with an intervening gouge by submitting a clay-rich layer of unconsolidated material to rapid rotary shear. However, only few of them have succeeded in experimentally producing CCAs [Boutareaud et al., 2008c].

[4] The aim of this contribution is first to compare natural CCAs in the Chelungpu fault gouge with experimental 
Table 1. Summary of the Main Experimental Parameters for All Conducted High-Velocity Experiments

\begin{tabular}{|c|c|c|c|c|c|}
\hline$\underline{\text { Run }}$ & Moisture Condition & $\begin{array}{c}\text { Slip Velocity } \\
\left(\mathrm{m} \mathrm{s}^{-1}\right)\end{array}$ & $\begin{array}{c}\text { Normal Stress } \\
(\mathrm{MPa})\end{array}$ & $\begin{array}{l}\text { Gouge Layer Thickness } \\
\text { After Experiment }(\mu \mathrm{m})\end{array}$ & $\begin{array}{c}\text { Total Displacement } \\
(\mathrm{m})\end{array}$ \\
\hline 569 & Saturated & 1.3 & 0.6 & 875 & 64.0 \\
\hline 576 & Saturated & 1.3 & 0.6 & - & 33.5 \\
\hline 572 & Saturated & 1.3 & 0.6 & - & 28.9 \\
\hline 581 & Nonsaturated & 1.3 & 0.6 & - & 34.6 \\
\hline 728 & Nonsaturated & 1.3 & 0.6 & 1000 & 26.6 \\
\hline 571 & Saturated & 0.9 & 0.6 & - & 64.4 \\
\hline 564 & Saturated & 0.9 & 0.6 & 1000 & 50.7 \\
\hline 521 & Saturated & 0.9 & 0.6 & 750 & 40.3 \\
\hline 527 & Saturated & 0.9 & 0.6 & 1050 & 48.6 \\
\hline 577 & Saturated & 0.9 & 0.6 & - & 30.5 \\
\hline 547 & Nonsaturated & 0.9 & 0.6 & 340 & 42.8 \\
\hline 574 & Nonsaturated & 0.9 & 0.6 & - & 23.3 \\
\hline 553 & Nonsaturated & 0.9 & 0.6 & 445 & 39.1 \\
\hline 545 & Nonsaturated & 0.9 & 0.6 & - & 36.9 \\
\hline 566 & Saturated & 0.09 & 0.6 & 875 & 4.3 \\
\hline 575 & Saturated & 0.09 & 0.6 & - & 4.0 \\
\hline 585 & Saturated & 0.09 & 0.6 & - & 3.7 \\
\hline 565 & Saturated & 0.09 & 0.6 & - & 3.7 \\
\hline 554 & Saturated & 0.09 & 0.6 & 815 & 2.5 \\
\hline 568 & Saturated & 0.09 & 0.6 & 940 & 2.5 \\
\hline 560 & Nonsaturated & 0.09 & 0.6 & 825 & 5.9 \\
\hline 550 & Nonsaturated & 0.09 & 0.6 & - & 4.3 \\
\hline 551 & Nonsaturated & 0.09 & 0.6 & 1175 & 9.6 \\
\hline 583 & Saturated & 1.3 & 1.2 & - & 24.6 \\
\hline 579 & Saturated & 1.3 & 1.2 & 750 & 26.0 \\
\hline 582 & Nonsaturated & 1.3 & 1.2 & - & 57.5 \\
\hline 580 & Nonsaturated & 1.3 & 1.2 & 900 & 29.3 \\
\hline 586 & Saturated & 0.9 & 1.2 & - & 37.1 \\
\hline 587 & Saturated & 0.9 & 1.2 & - & 28.8 \\
\hline 549 & Saturated & 0.09 & 1.2 & 625 & 8.3 \\
\hline 548 & Saturated & 0.09 & 1.2 & 500 & 10.6 \\
\hline 584 & Saturated & 0.09 & 1.2 & - & 2.8 \\
\hline 567 & Saturated & 0.09 & 1.2 & 1150 & 2.0 \\
\hline 559 & Nonsaturated & 0.09 & 1.2 & - & 4.3 \\
\hline 578 & Nonsaturated & 0.09 & 1.2 & 1025 & 2.6 \\
\hline$\underline{558}$ & Nonsaturated & 0.09 & 1.2 & - & 1.3 \\
\hline
\end{tabular}

CCAs obtained from additional high-velocity rotary shear experiments, second to identify the relevant parameters responsible for their formation in light of the low-velocity double-shear experiments for which no CCA could be observed, and finally, to propose a scenario for the formation of these peculiar microstructures.

\section{Geological and Experimental Context of CCAs}

[5] The natural CCAs come from the same fault zone sampled by two boreholes of the Taiwan Chelungpu Drilling Project (TCDP): FZA1111 (Hole A, Fault Zone at $1111 \mathrm{~m}$ ) and FZB1136 (Hole B, Fault Zone at $1136 \mathrm{~m}$ ). CCAs have been observed in the $M_{w} 7.61999$ Chi-Chi earthquake PSZ in FZA1111 and in an older gouge layer corresponding to a past earthquake in FZB1136 [Boullier et al., 2009]. The PSZ of the Hole A was characterized by a total displacement of $5 \mathrm{~m}$ at the TCDP Hole A location [Yu et al., 2001] and a high slip velocity (up to $4 \mathrm{~m} \mathrm{~s}^{-1}$ ), for an important temperature increase (up to $400^{\circ} \mathrm{C}$ ) [Mishima et al., 2006].

[6] To experimentally reproduce CCAs, two major tests have been conducted: high-velocity rotary shear experiments and low-velocity double-shear experiments. For these tests, we used distilled water as pore fluid and the same natural gouge. This gouge comes from a natural clay-rich gouge sampled from the Usukidani fault, which is an active fault of southwest Japan [Boutareaud et al., 2008b]. It has been sieved in order to first eliminate clasts larger than $80 \mu \mathrm{m}$ (clay fraction represents $15.7 \%$ ), and second to obtain a starting gouge material free from any preferred orientation.

[7] Thirty-five representative high-velocity rotary shear experiments have been conducted on rotating cylindrical samples (Table 1) [Boutareaud, 2007], using a high-speed rotary shear apparatus [Shimamoto and Tsutsumi, 1994]. The experimental fault is composed of two $24.4 \mathrm{~mm}$ diameter solid granite cylinders that are first ground to obtain rough wall surfaces, and then reassembled with an intervening layer of calcite $0.8 \mathrm{~mm}$ thick clay-rich gouge. A Teflon ring surrounds the simulated fault in order to avoid gouge or liquid water expulsion during rotation. However, this does not constitute a seal for water vapor. The assembly is then placed in the rotary shear apparatus, where one cylinder remains stationary while the other rotates (see Boutareaud et al. [2008c] for experimental setup and procedure). The area of simulated faults is $468 \mathrm{~mm}^{2}$, for an unlimited displacement of $10-60 \mathrm{~s}$ of usual test duration. Slip velocity was fixed at $0.09 \mathrm{~m} \mathrm{~s}^{-1}, 0.9 \mathrm{~m} \mathrm{~s}^{-1}$, and $1.3 \mathrm{~m} \mathrm{~s}^{-1}$ under 0.6 and $1.2 \mathrm{MPa}$, in initially nonsaturated (room humidity; typically $60 \%$ relative humidity) and saturated conditions and at room temperature.

[8] The duration of these experiments and the observed dramatic dynamic stress drop (i.e., an exponential decrease of the dynamic friction coefficient from a peak value down 


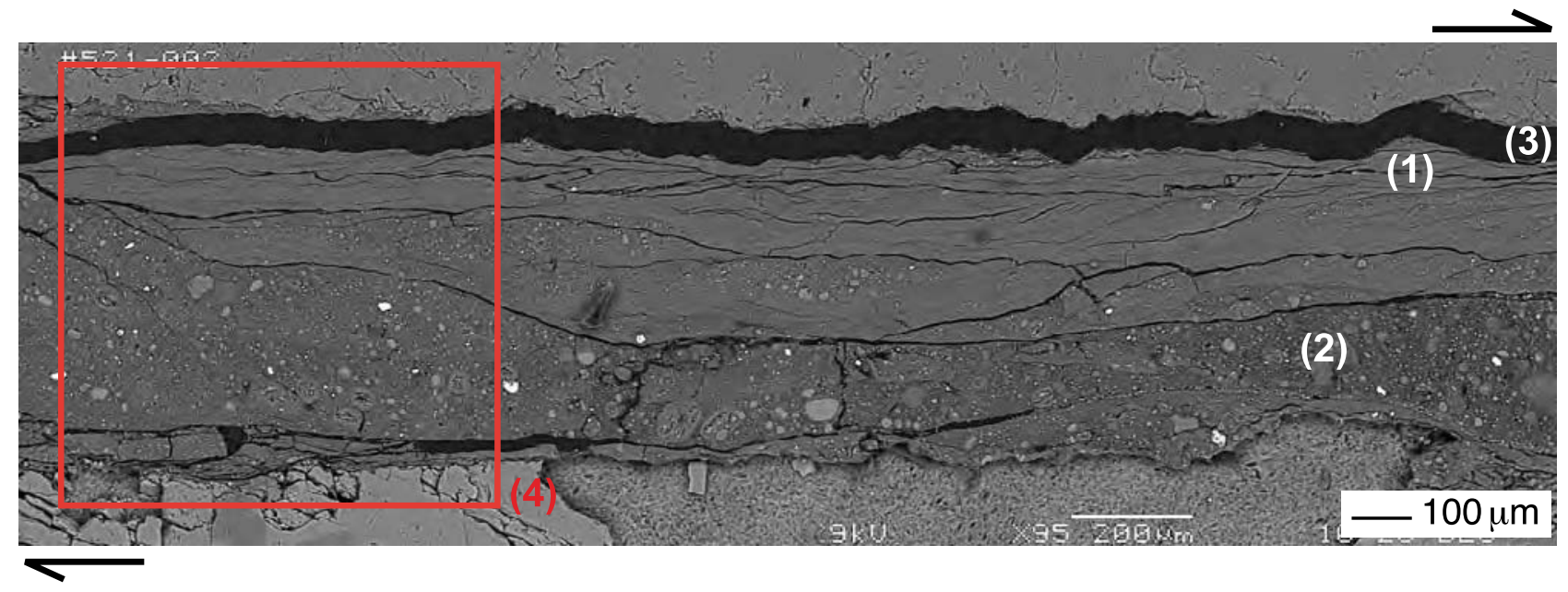

Figure 1. SEM image of a view part of the fault zone from run 521, showing the typical ultrafinegrained foliated gouge zone (1) and CCA-bearing gouge layer (2). Section is perpendicular to the fault zone and parallel to the slip direction at the boundary part of the cylindrical fault assembly. The top rock corresponds to the rotating side and the bottom rock to the stationary side of the experimental assembly. (3) Epoxy layer. (4) Location of the area observed in Figure 11.

to a steady state value) differ from 0.09 to $1.3 \mathrm{~m} \mathrm{~s}^{-1}$, but remain representative to the typical risetime and breakdown stress drop of large earthquakes, respectively, determined on the basis of seismological recordings [Mizoguchi et al., 2007b].

[9] On the basis of a computation of a 2-D framework extending the Lachenbruch's [1980] model, using SETMP software to solve the heat equation by finite element method [Calugaru et al., 2003], temperature evolution has been calculated for the whole sheared gouge layer and validated by comparing computed temperatures with thermocouple measurements [Boutareaud, 2007; Boutareaud et al., $2008 \mathrm{c}]$.The numerical method considers that all frictional work is converted into heat and temperature changes are only caused by heat production and heat diffusion. Then, the heat source term is proportional to the measured shear stress and the radial position. The temperature evolution of only two points located on the simulated PSZ (hereafter narrow ultrafine-grained foliated gouge layer) is investigated: one at the center of the cylinder $\left(T_{c}\right)$, which corresponds to the minimum radial velocity, and the other at the periphery of the cylinder $\left(T_{p}\right)$, which corresponds to the maximum radial velocity. Temperatures have been reported here for the $0.09 \mathrm{~m} \mathrm{~s}^{-1}$ experiments at $0.6 \mathrm{MPa}$, for which postrun thin sections of initially nonsaturated conditions show CCAs (e.g., layer 2 in Figure 1), whereas initially saturated conditions do not show any CCA (see Figure 4). In initially nonsaturated conditions, the maximum temperature reached by exponential increase after $60 \mathrm{~s}$ by $T_{p}$ is $209^{\circ} \mathrm{C}$, whereas it is $61^{\circ} \mathrm{C}$ for $T_{c}$. In initially saturated conditions, the maximum temperature reached after $60 \mathrm{~s}$ by $T_{p}$ is $97^{\circ} \mathrm{C}$, whereas it is $37^{\circ} \mathrm{C}$ for $T_{c}$ (Figure 2 ).

[10] It is remarkable that whatever slip velocity and initially humid conditions, all of the high-velocity experiments, except the $0.09 \mathrm{~m} \mathrm{~s}^{-1}$ experiments in initially saturated conditions, show that the simulated fault zone experienced dilatancy in the first meters of displacement [Boutareaud et al., 2008c].
[11] Five low-velocity double-shear experiments have been conducted using a biaxial frictional apparatus at Kyoto University (Table 2). The experimental fault is double at the interface of three rectangular blocks of gabbro, with a size of $20 \times 40 \times 60 \mathrm{~mm}$ for right and left blocks and $39 \times 40 \times$ $70 \mathrm{~mm}$ for the central block. Normal stress is applied horizontally by a hydraulic jack, and shear stress is applied vertically by the use of an electric motor and a gear system (see Mair and Marone [1999] for complete experimental setup and procedure). Experiments were performed in initially nonsaturated (room humidity; typically $60 \%$ relative humidity) and saturated conditions, at room temperature. The area of simulated faults is $20 \mathrm{~cm}^{2}$, for a maximum displacement limited at $2 \mathrm{~cm}$, and a thickness of about $1 \mathrm{~mm}$. Load point velocity was fixed at $0.014,0.14,1.4$, and $14 \mu \mathrm{m} \mathrm{s}^{-1}$ and normal load was fixed at 20,30 , or $45 \mathrm{MPa}$ (Table 2).

[12] No dramatic slip weakening could be observed at the starting of these experiments, for an applied constant load point velocity.

[13] No temperature measurement or calculation has been done for this type of experiment. However, a rough calculation following the first term of equation (1) of Noda and Shimamoto [2005] would give a maximum temperature increase of $0.2^{\circ} \mathrm{C}$ for experiments conducted at $14 \mu \mathrm{m} \mathrm{s}^{-1}$ and $30 \mathrm{MPa}$ after $18 \mathrm{~mm}$ of displacement (with friction coefficient $=0.8$, gouge heat capacity $=1000 \mathrm{~J} \mathrm{~kg}^{-1} \mathrm{~K}^{-1}$, and gouge density $=2000 \mathrm{~kg} \mathrm{~m}^{-3}$ ). This is consistent with the maximum temperature change of $5.4^{\circ} \mathrm{C}$ measured by Mair and Marone [2000] for similar experiments conducted at $0.3-3 \mathrm{~mm} \mathrm{~s}^{-1}$ and normal load fixed at $70 \mathrm{MPa}$ after $18 \mathrm{~mm}$ of displacement. No CCA could be observed on any postrun thin sections from our experiments (e.g., Figure 3).

\section{Microstructures of CCAs and Ultrafine-Grained Foliated Gouges}

[14] Thin section observation by SEM shows that the starting gouge powder for rotary shear experiments does not 


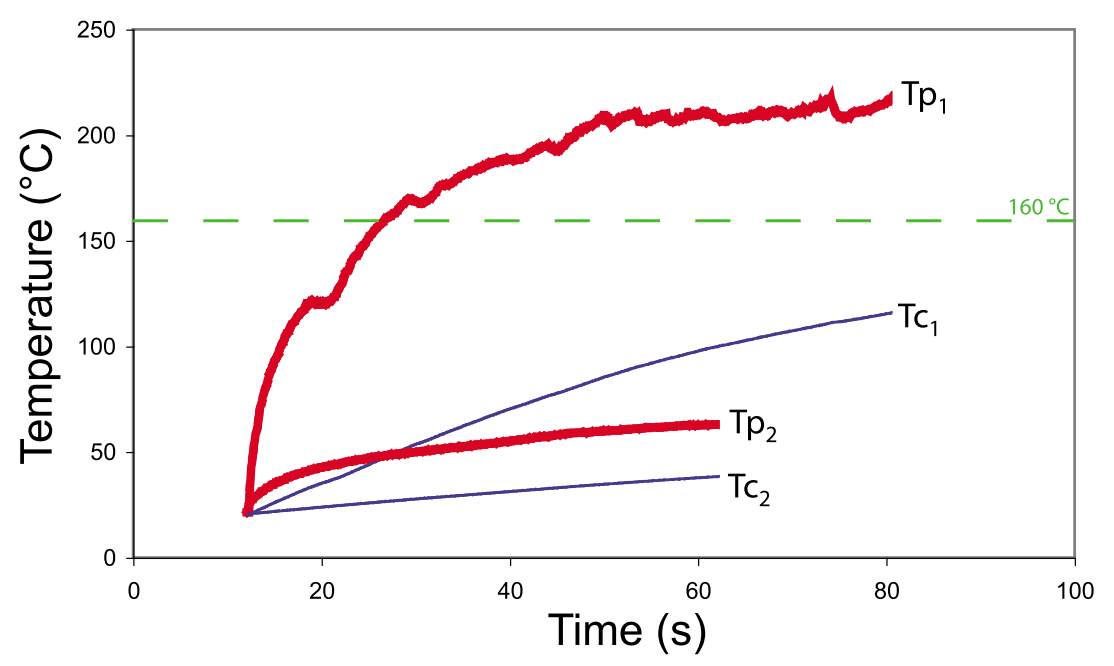

Figure 2. Temperature evolution calculated at the center (revolution axis, $T_{c}$ ) and at the periphery $\left(T_{\underline{p}}\right)$ of the rotating cylinder as a function of time, for two representative experiments conducted at $0.09 \mathrm{~m} \mathrm{~s}^{-1}$ and 0.6 MPa, in initially nonsaturated conditions (subscript 1 for 560) and initially saturated conditions (subscript 2 for 566), respectively. The calculation follows procedure described by Boutareaud et al. [2008a].

contain any CCA. The estimated surface percentage occupied by CCAs on thin section is much lower in the natural gouge $(<10 \%)$ than in the postexperiment gouges (from $\sim 11 \%$ at $0.09 \mathrm{~m} \mathrm{~s}^{-1}$ in initially nonsaturated conditions, up to $\sim 39 \%$ at $1.3 \mathrm{~m} \mathrm{~s}^{-1}$ in initially saturated conditions; Figure 4). The maximum diameter of the inner cores (central clasts hereafter) is $150 \mu \mathrm{m}(50 \mu \mathrm{m}$ as a mean) for natural CCAs, whereas it is $375 \mu \mathrm{m}$ (20 $\mu \mathrm{m}$ as a mean) for the experimental CCAs. Normalized and inverse cumulative particle size distribution in the postexperiment gouges (see Keulen et al. [2007] for the method) for tests conducted at $0.09,0.9$, and $1.3 \mathrm{~m} \mathrm{~s}^{-1}$ shows an increase in the diameter of postexperiment particles with respect to the diameter of starting gouge particles, regardless of initially humid conditions and slip velocity (Figure 5).

[15] According to X-ray diffraction (XRD) analyses (CuK $\alpha$ radiation, with an accelerating voltage of $40 \mathrm{kV}$ and a filament current of $40 \mathrm{~mA}$ ), the two gouges (i.e., natural and postexperiment gouges) are composed of quartz, K-feldspar, plagioclase, calcite, chlorite, muscovite, pyrite, kaolinite, illite, and undefined illite-smectite mixed layers for the major species (Figure 6). No lime, hydrated lime, siderite nor glassy material is clearly revealed on postexperiment gouges. Detailed investigations by scanning electron microscope (SEM) and cathodoluminescence (not reported) show first that the central monomineralic clasts are rounded to sub-rounded and consist essentially of quartz, calcite, or K-feldspar, and second that the central polymineralic clasts are constituted by clay particles exhibiting a strong preferred orientation with few fragments of quartz, calcite or K-feldspar.

[16] Energy dispersive X-ray spectrometry (EDX-SEM) element composition mappings conducted on the two types of monomineralic CCAs (FZB1136 and 521 for natural and experimental CCAs, respectively) display a higher relative atomic density of $\mathrm{Al}, \mathrm{Mg}$, and $\mathrm{Fe}$ elements in the $\mathrm{CCA}$ cortex than those in the gouge matrix (Figure 7). Additionally, under crossed polarizers combined to a gypsum plate, a remarkable pair of blue to yellow quadrants in the cortex highlights the preferred orientation of clays concentrically coating the central clast (Figure 8). The thickness of this annular cortex rarely overpasses the value of $5 \mu \mathrm{m}$ for natural CCAs and $15 \mu \mathrm{m}$ for experimental CCAs.

[17] Two focused ion beam (FIB) sections of about 100 $\mathrm{nm}$ in thickness were extracted from a natural (FZB1136) and an experimental (521) monomineralic CCA, respectively (shown in Figures $7 \mathrm{a}$ and $7 \mathrm{~b}$ ). Transmission electron microscopy (TEM) observations of these two FIB sections show an alternation of comparable concentric zones from the clastcortex interface toward the surroundings (Figures 9a and 9e): (1) a large rounded to subrounded central clast that is moderately fractured, (2) a micrometer-thick (1-3 $\mu \mathrm{m}$ for natural CCAs, $\sim 100-400 \mathrm{~nm}$ for experimental CCAs) cataclastic porous layer at the edge of the central clast, which is chemically similar to the central clast and made of very small crystal fragments as shown by the electron diffraction

Table 2. Summary of the Main Experimental Parameters for all Conducted Low-Velocity Experiments

\begin{tabular}{ccccc}
\hline Run & Moisture Condition & $\begin{array}{c}\text { Slip Velocity } \\
\left(\mu \mathrm{m} \mathrm{s}^{-1}\right)\end{array}$ & $\begin{array}{c}\text { Normal Stress } \\
(\mathrm{MPa})\end{array}$ & $\begin{array}{c}\text { Gouge Layer Thickness } \\
\text { After Experiment }(\mu \mathrm{m})\end{array}$ \\
\hline BAF075 & Saturated & $0.014-0.14$ & 20 & 348 \\
BAF086 & Saturated & $0.014-1.4$ & 45 & 478 \\
BAF088 & Saturated & $0.014-1.4$ & 45 & 283 \\
BAF093 & Nonsaturated & $0.014-14$ & 30 & 304 \\
BAF094 & Saturated & $0.014-0.14$ & 20 & 10.4 \\
\hline
\end{tabular}



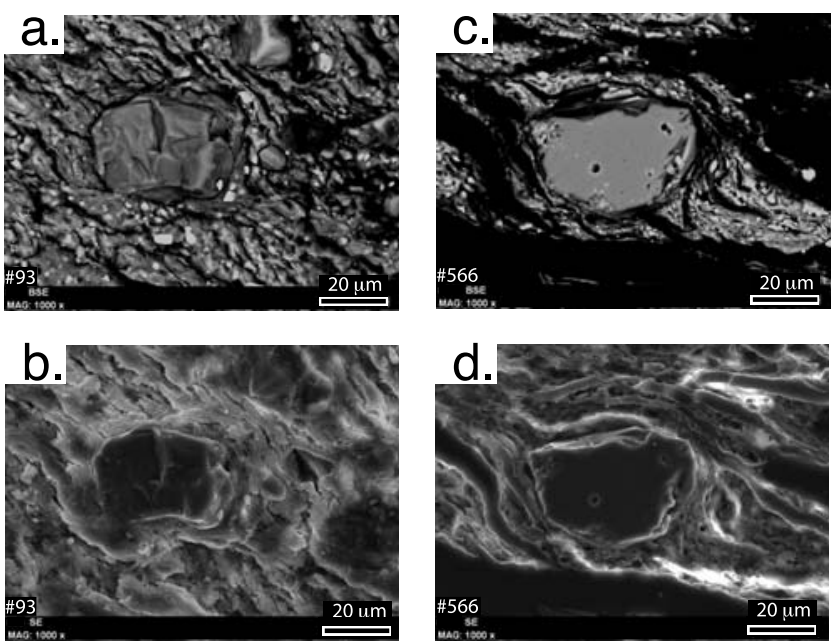

Figure 3. BSE and SEM images showing clasts free from any aggregated cortex, representative of experiments con-

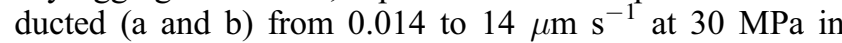
initially nonsaturated conditions (for BAF93) and (c and d) at $0.09 \mathrm{~m} \mathrm{~s}^{-1}$ and $0.6 \mathrm{MPa}$ in initially saturated conditions (for 566).

patterns (Figures 9c and 9f), (3) a 20-50 nm thick layer of clays that shows a strong preferred orientation parallel to the clast margin and that surrounds the cataclastic layer (Figures 9c and 9f), and (4) a heterogeneous surrounding cortex composed essentially of illite-smectite mixed layers showing first an average preferred orientation with their (001) planes subparallel to the central clast margin, and second a random alternation of concentric micrometric porous and dense layers, well-developed on experimental
CCAs (Figures 9d and 9h). These former layers can be occasionally absent because of a hole, or locally irregularly amorphous on electron diffraction (Figure 9g). Hence, as a rule, crystallinity of clays that compose the cortex of natural CCAs is remarkably complete, whereas it remains partial for experimental CCAs. The cortex of the two types of CCAs commonly includes nanometric mineral fragments (from 10 up to $1000 \mathrm{~nm}$ ) of quartz, feldspar, calcite, or chlorite embedded in a clay material (Figures $9 \mathrm{~d}$ and $9 \mathrm{~h}$ ). In addition, clasts of chlorite are usually hole-scattered, which is typical of a thermal dehydration process.

[18] Detailed observations of the postexperiment gouges also show a narrow and ultrafine-grained foliated gouge layer (layer 1 in Figure 1). This gouge layer is composed of strongly oriented clay particles parallel to the fault gouge boundaries and mixed with small (about $1 \mu \mathrm{m}$ ) rounded mineral fragments. The foliated gouge is not mixed within but crosscuts the nonfoliated gouge in an anastomosed network. It is observed along one or both granite-gouge boundaries, and it is generally thicker on the rotating side than on the stationary side. No CCAs are observed in the foliated gouge. Microprobe analyses indicate that the foliated gouge has the same chemical composition as the nonfoliated gouge [Boutareaud, 2007]. At least, it is remarkable that the central clast of the largest experimental CCAs is always composed of a fragment derived from this foliated gouge (Figure 10b), with strong similar characteristics to the largest natural CCAs (Figure 10a).

[19] We used a Bruker Optics infrared (IR) microscope (Hyperion) to measure the transmittance of IR-light passing through a gouge postexperiment thin section (521 and 728). Resulting transmittance data are converted into absorbance (Abs) to determine accurately the absorbance wavelength of $\mathrm{H}_{2} \mathrm{O}$ and $\mathrm{OH}$ peaks (see Castro et al. [2008] for the method).

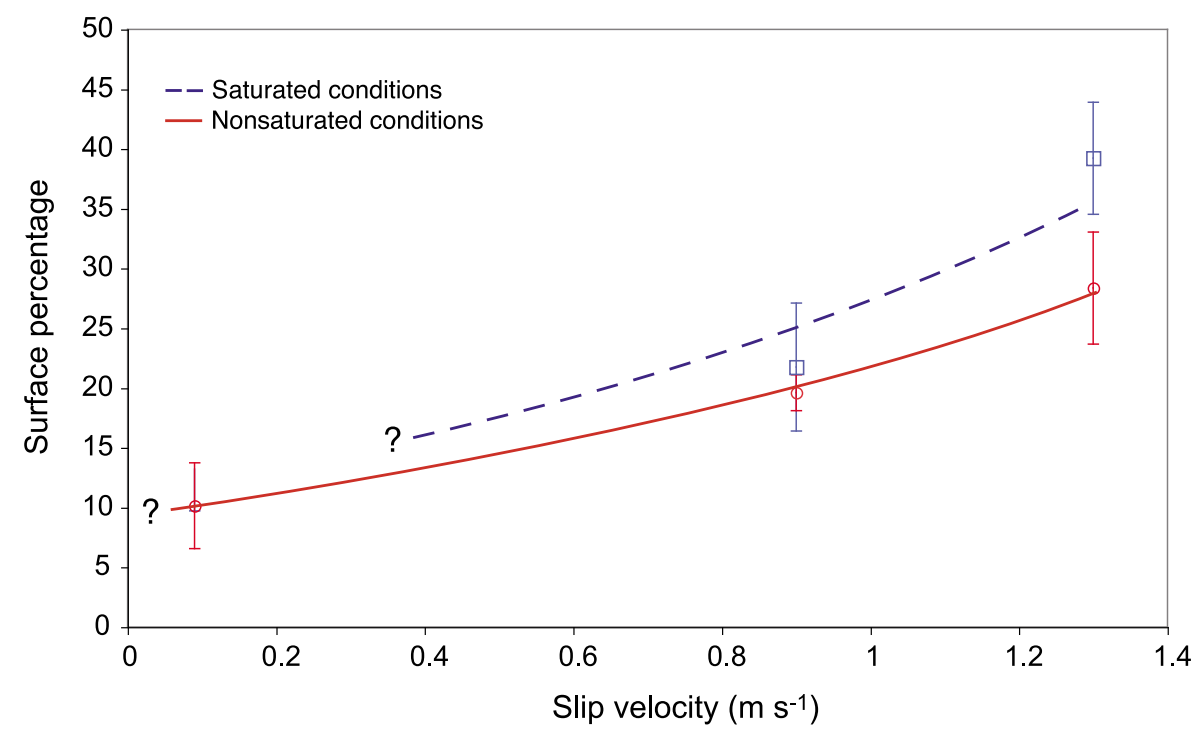

Figure 4. Graph showing the CCA abundance for most of experiments conducted at 0.09 , 0.9, and $1.3 \mathrm{~m} \mathrm{~s}^{-1}$ confined at $0.6 \mathrm{MPa}$. On the basis of images derived from drawings using Illustrator software, we calculated CCA abundance by measuring the ratio the surface occupied by CCAs to the total fault zone surface on thin section, under the optical microscope or SEM using ImageJ analysis software [Boutareaud et al., 2007]. Dashed and solid lines correspond to initially saturated and initially nonsaturated conditions, respectively. The question marks indicate the potential starting apparition of CCAs related to the critical temperature for pore water phase transition (see text for discussion). 


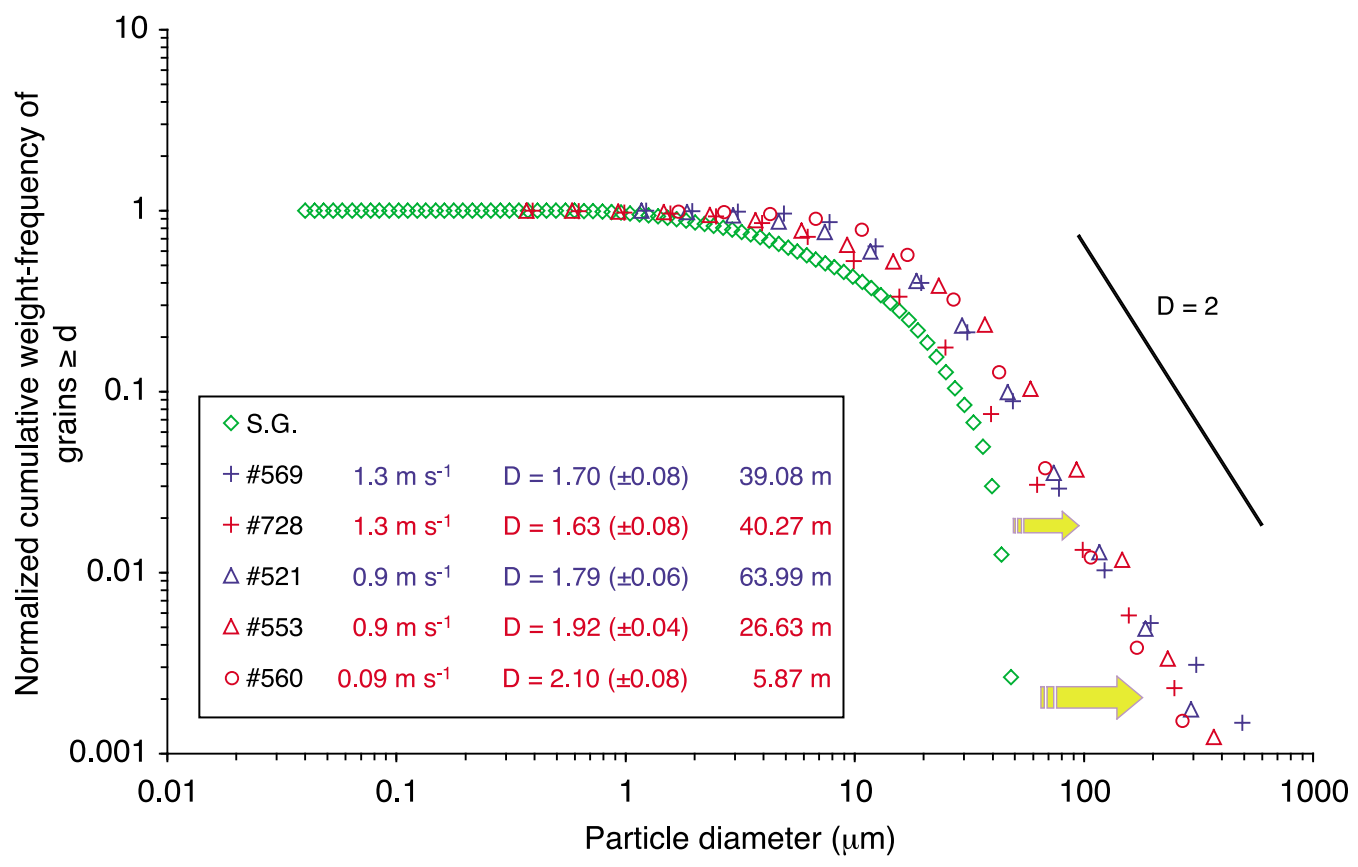

Figure 5. Graph showing the normalized and inverse cumulative weight particle size frequency of the starting gouge power and the postexperiment gouge PSZ for representative experiments conducted at $0.09,0.9$, and $1.3 \mathrm{~m} \mathrm{~s}^{-1}$ confined at $0.6 \mathrm{MPa}$ for initially saturated (blue) and initially nonsaturated (red) conditions. Particle abundance (without any distinction between CCAs or clasts) is estimated from SEM and optical photomicrographs using ImageJ analysis software but laser granulometry (Beckmann-Coulter LSD230) and ultrasound box for the starting gouge powder [Boutareaud et al., 2008c]. Blue and red correspond to initially saturated and initially nonsaturated conditions, respectively, and S.G. stands for starting gouge powder. $D$ number indicates the calculated fractal dimension in two dimensions \pm 1 standard deviation, i.e., the slope of the corresponding best fit curve. Last numbers correspond to the total slip displacement.

However, gouge layers on postexperiment thin sections are neither perfectly planar nor homogeneous, but rather swelling and locally compacted. Therefore, to compare one gouge area with the other, we calculated the ratio of $\mathrm{Abs} \mathrm{OH}$ peak values on $\mathrm{Abs} \mathrm{H}_{2} \mathrm{O}$ peak values, considering that there was no release of $\mathrm{OH}$ (radical) during rotary shear experiments from clays (i.e., temperature did not overpass $550^{\circ} \mathrm{C}$ ). From this procedure, it results that (Figure 11): (1) a high ratio value corresponds to a small amount of interlayer water within clay minerals (i.e., low hydration state of clays); and (2) conversely, a low ratio value corresponds to a large amount of interlayer water within clay minerals (i.e., high hydration state of clays). This method of investigation shows that the hydration state of the ultrafine-grained foliated gouge is about half the hydration state of the nonfoliated gouge that contains CCAs (Figure 11a). In addition, it is remarkable that the central part of CCAs with a foliated gouge as central clast exhibits a very low hydration state, whereas the cortex shows a higher hydration state, and the surrounding gouge matrix shows a more higher hydration state (see 4 in Figure 11b).

\section{Interpretations and Discussion}

\subsection{Formation of CCAs}

[20] The measured mean size of the central monomineralic clasts of quartz for natural and experimental CCAs is in the range of the size of particles produced by crushing (from 3 to $100 \mu \mathrm{m}$ with $25 \mu \mathrm{m}$ as a mean according to Jefferson et al. [1997]), suggesting that the central clasts and their initial size reduction essentially result from fragmentation and comminution mechanisms under elastic compressive loading, which is inversely related to confining pressure and shear displacement [Engelder, 1974; Anderson et al., 1983]. In the meantime, the presence of nanometric mineral fragments of quartz observed within the cortex of natural and experimental CCAs suggests that shock-loading and subcritical crack growth processes in compression may occur for particles lower than the griding limit of $1 \mu \mathrm{m}$ [Sammis and Ben-Zion, 2008] during fragmentation and comminution.

[21] The fracture probability of a grain is known to be directly controlled by the relative density and size of the nearest neighboring clasts [Sammis et al., 1987; Mair and Hazzard, 2007; Sammis and King, 2007], and the fractal dimension of grain size distribution to increase systematically with increasing strain [Abe and Mair, 2005; Marone and Scholz, 1989] at least for particles larger than $1 \mu \mathrm{m}$ [Keulen et al., 2007]. To the contrary, a decrease of the fractal dimension $D$ in the postexperiment gouge from 0.09 to $1.3 \mathrm{~m} \mathrm{~s}^{-1}$ can be observed, which is an increase of the diameter for largest particles (Figure 5). This unexpected result, combined to the presence of the nanometric clasts embedded within the cortex of the two types of CCAs, suggests the occurrence of an aggregation process that allows cohesion of wear debris particles to the growing cortex from the surroundings. The critical parameters that control this process need to be determined. 


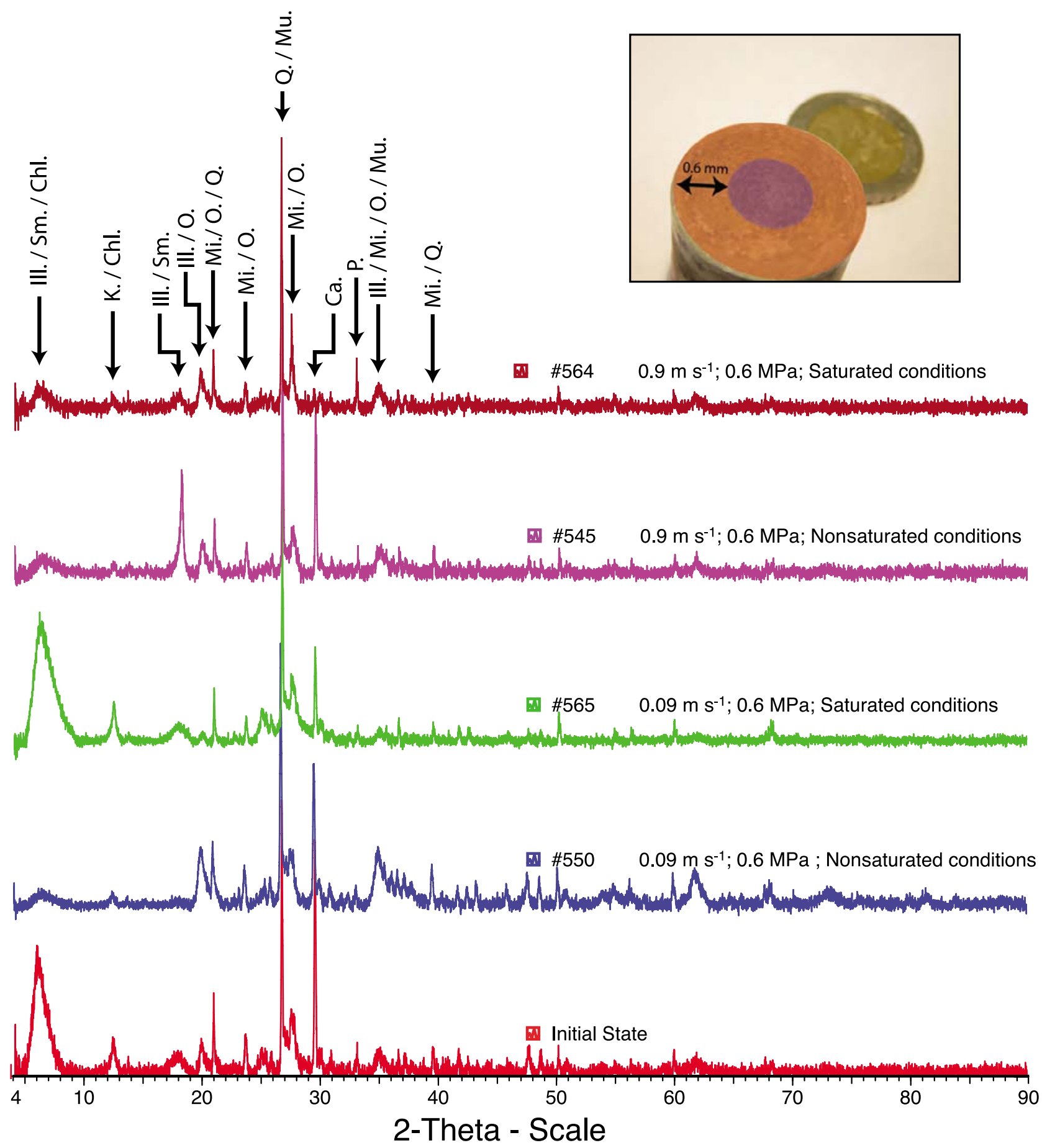

Figure 6. Comparison of X-ray diffraction patterns of postexperiment gouges, for representative experiments conducted at the two seismic velocities of 0.09 and $0.9 \mathrm{~m} \mathrm{~s}^{-1}$ at $0.6 \mathrm{MPa}$. The peaks intensities are normalized to the main quartz peak of the initial state. Ill, illite; Sm, smectite; Chl, chlorite; $\mathrm{K}$, kaolinite; $\mathrm{O}$, orthoclase; $\mathrm{Mi}$, microcline; $\mathrm{Q}$, quartz; $\mathrm{Mu}$, muscovite; $\mathrm{Ca}$, calcite; $\mathrm{P}$, pyrite. Inset shows a simulated fault surface once the upper rock cylinder has been removed. Slickensides can be observed from the periphery to the center of the simulated fault surface. Orange and pink correspond to the peripheral and the central parts of the fault, respectively, which have been sampled after experiments for $\mathrm{X}$-ray diffraction analyses.

[22] According to the observed surface abundance of CCAs in two-dimensions (Figure 4), initially humid conditions and slip velocity appear to play a major role in their apparition. Similarly, according to the cumulative grain-size distribution of CCAs, their development (i.e., their abundance) seems to be controlled by additional parameters. One of these parameters might be the amount of total displacement. The lower surface percentage of CCAs observed 
a.
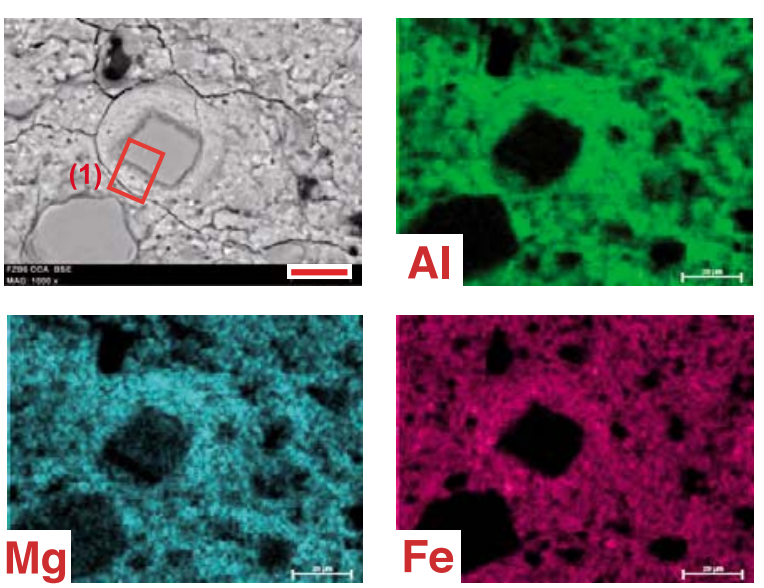

b.
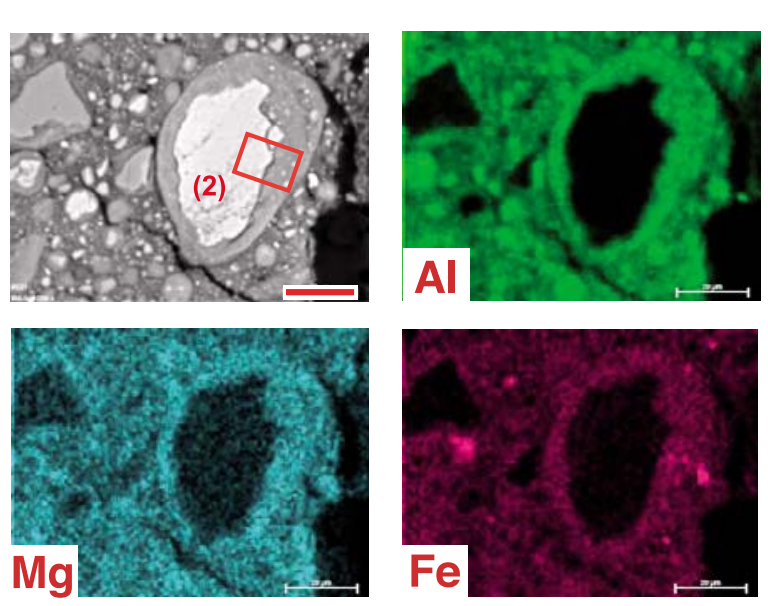

Figure 7. EDX-SEM element composition mappings of a typical CCA, in (a) natural and (b) experimental conditions. Figure 7a comes from the gouge PSZ of the Chelungpu fault (gouge retrieved from the TCDP Hole B at $1136 \mathrm{~m}$ depth, i.e., FZB1136). Figure $7 \mathrm{~b}$ comes from a postexperiment gouge sheared at $0.9 \mathrm{~m} \mathrm{~s}^{-1}$ in initially saturated conditions (521). Only Al, $\mathrm{Mg}$, and Fe elements show a strong signal for the cortex of CCAs. The red bar on the bottom right is $20 \mu \mathrm{m}$. Points 1 in Figure $7 \mathrm{a}$ and 2 in Figure $7 \mathrm{~b}$ locate FIB sections observed by TEM in Figure 9a and Figure 9b, respectively.

within the PSZ of the Chelungpu fault for a lower amount of displacement during the Chi-Chi earthquake is consistent with such experimental results.

[23] Comparing the $0.09 \mathrm{~m} \mathrm{~s}^{-1}$ experiments for saturated and nonsaturated conditions, it appears that for the whole duration of the two runs, calculated temperatures of the two sheared gouges are always higher for the nonsaturated conditions with respect to the saturated conditions (Figure 2). According to the water phase diagram [Wagner and Pruss, 2002], at $0.6 \mathrm{MPa}$ the water liquid-to-vapor phase transition occurs at $160^{\circ} \mathrm{C}$. Our calculation shows that this critical temperature is only reached by the peripheral gouge for nonsaturated experiments (after $27.3 \mathrm{~s}$, i.e., is after $1.3 \mathrm{~m}$ of the effective displacement). Concerning low-velocity experiments, the maximum temperature increase at $30 \mathrm{MPa}$ is $0.2^{\circ} \mathrm{C}$ (see section 2), with no water phase change expected before $370^{\circ} \mathrm{C}$ [Wagner and Pruss, 2002]. On the basis of post-run thin section observations of low- and high-velocity experiments, we can say that CCAs are only present for tests conducted at seismic velocities (i.e., at $0.09,0.9$, and $1.3 \mathrm{~m} \mathrm{~s}^{-1}$ ), except for the experiments in saturated conditions at $0.09 \mathrm{~m} \mathrm{~s}^{-1}$. This clearly shows that a critical temperature of gouge water phase transition is needed for the formation of CCAs.

[24] The nearly perfect sphere shape, the large size of some central clasts, and the apparent individual disjunction of CCAs indicate that they were packed loosely enough and dispersed during shearing to avoid intense grain contact regime and consecutive comminution. The nearly perfect sphere shape of CCAs, the concentrically coating of cortex layers, the random radial alternation of the micrometric porous and dense clay layers of the CCA cortex, their nearly constant thickness, and the similar chemical composition of the cortex compared with the surrounding gouge suggest that fragmentation-survivor clasts distributed throughout the entire gouge layer are individually wrapped by the successive
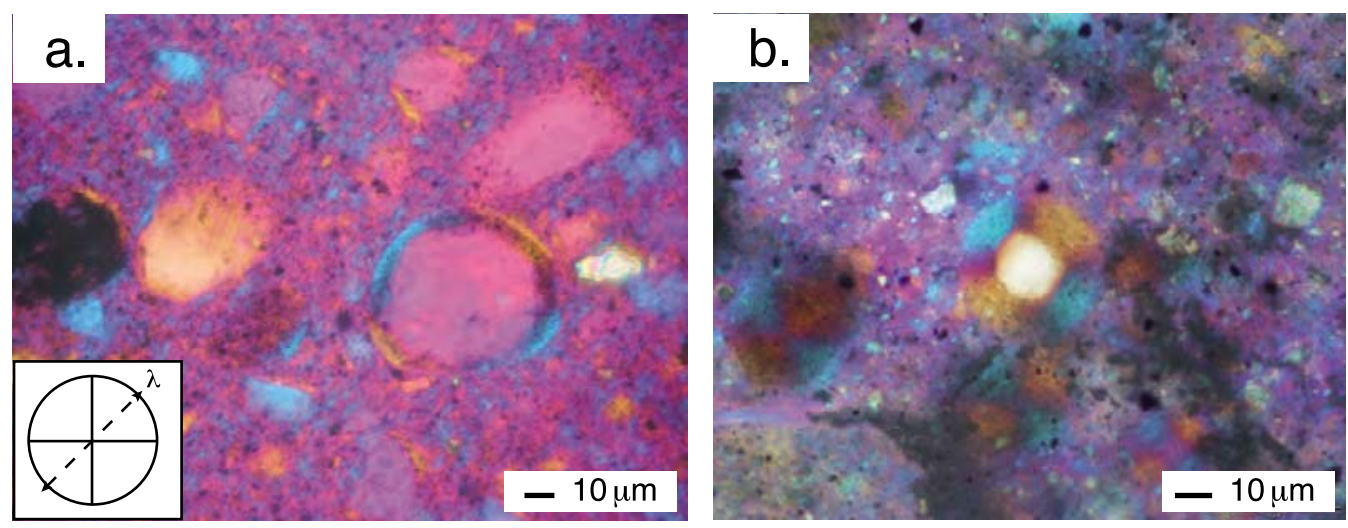

Figure 8. Microphotographs under crossed polars with a gypsum plate of CCAs. (a) Natural CCA from the TCDP Hole A retrieved from $1111 \mathrm{~m}$ depth (FZA1111). (b) Experimental CCA from a run conducted from $0.9 \mathrm{~m} \mathrm{~s}^{-1}$ at $0.6 \mathrm{MPa}$ in initially nonsaturated conditions (553). Inset shows the positions of crossed polars and gypsum plate. 

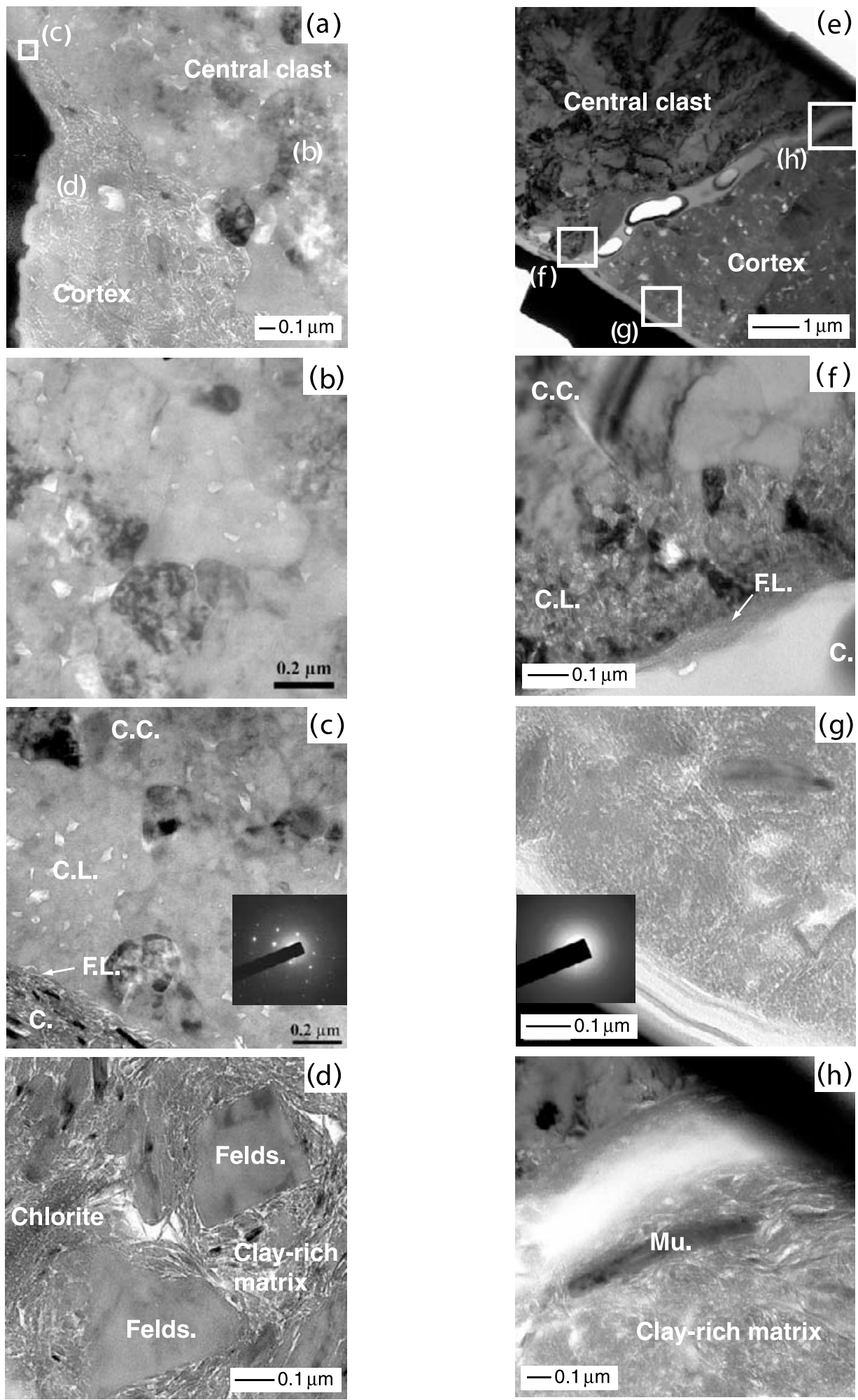

Figure 9 

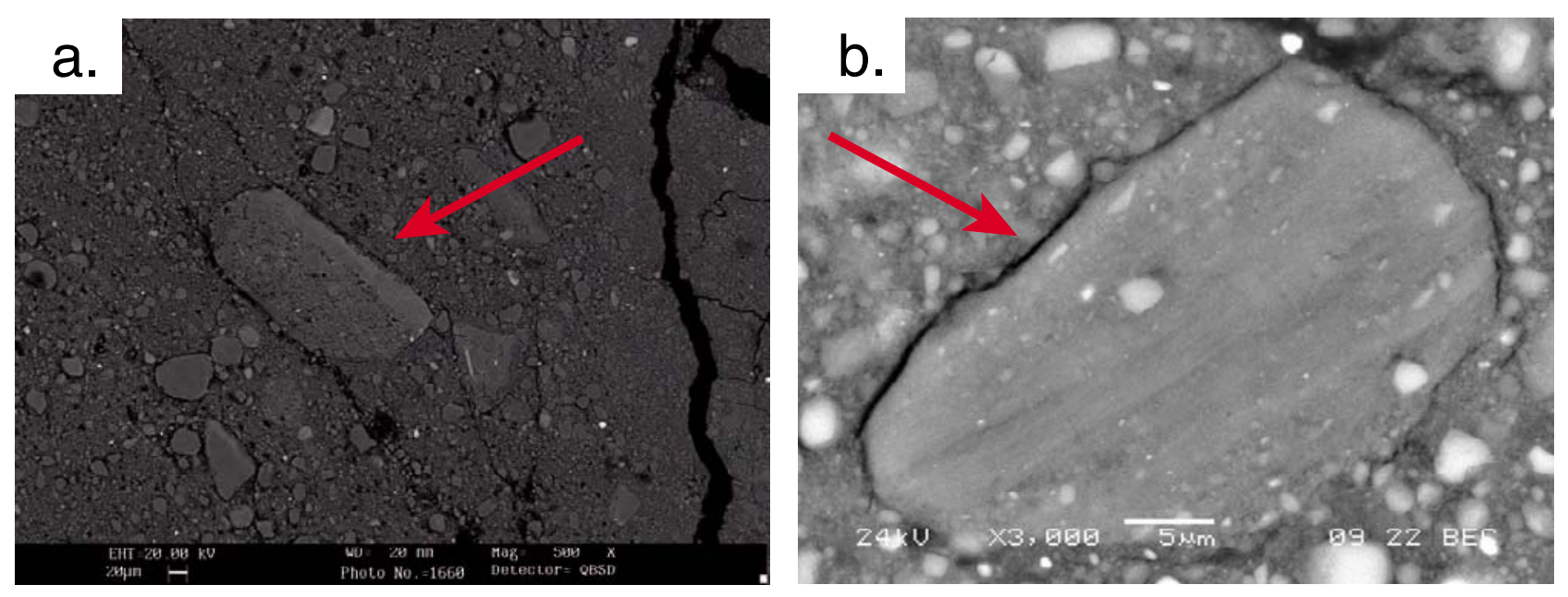

Figure 10. Red arrows indicate CCAs showing a foliated gouge fragment as central clast. (a) Single natural CCA from the TCDP Hole B retrieved from $1136 \mathrm{~m}$ depth (FZB1136). (b) Single experimental CCA from a run conducted from $0.09 \mathrm{~m} \mathrm{~s}^{-1}$ at $0.6 \mathrm{MPa}$ in initially nonsaturated conditions (560).

clay layers thanks to a dynamic rotation of central clasts, i.e., is a rolling process. According to Mair and Marone [2000] and Mair et al. [2002], mechanical rotation of clasts in a granular sheared system is effective only once clasts dominate with a sub-rounded shape. This result suggests that it is only after the initiation of this rolling process that survivor clasts distributed throughout the entire gouge layer can be individually wrapped by the successive concentric layers of clays. Additional space to allow grain rolling can be provided by the observed dilatancy of the simulated fault zone due to the water liquid-to-vapor phase transition, which involves an increase of the initial water volume by a factor of 10 , which is an increase of the gouge pore fluid pressure. This is thermal pressurization [Sibson, 1973]. This phenomenon is validated by first the observed high-amplitude peak events in axial displacement [Boutareaud et al., 2008c], and second the observed released of water vapor monitored by Brantut et al. [2008] during similar nonsaturated friction experiments.

[25] The lower surface percentage of CCAs obtained at $0.09 \mathrm{~m} \mathrm{~s}^{-1}$ in nonsaturated conditions, with respect to higher slip velocities, can be explained by the lower heat produced by friction, which leads to a lower excess pore fluid pressure and a moderate slip-weakening effect [Boutareaud, 2007].

[26] The nanometric to micrometric cataclastic layer observed at the edge of the central clasts might constitute the result of grain collision during the early stage of rolling process. Moreover, the absence of any obvious fracture through central clasts of CCAs indicates the rapid occurrence of a wrapping process during the establishment of rolling process, which highly reduces fracturing probability and the subsequent size reduction of grains by lowering intense stress contact at the clast boundaries [Mandl et al., 1977].

[27] In the following section, we study the role of electrochemical properties of water on the formation and development of CCAs.

\subsection{Aggregation Process}

[28] CCAs exhibit similar structural characteristics to the volcanic accretionary lapilli described by Schumacher and Schmincke [1995]. This suggests comparable development processes for the CCAs with frequent collisions of liquidcoated particles in a turbulent mixture of solid particles in a critical reactive liquid-vapor water medium (Figure 12). Therefore, the CCA aggregation process is expected to be controlled by the combination of two major physical forces [Boutareaud et al., 2008c]. The first physical forces likely to be efficient are electrostatic forces that attract long-ranged (>500 $\AA$ ) extremely fine mineral fragments from the surroundings. The second are capillary forces that (1) bind shortranged $(<100 \AA)$ attracted fragments to the central clast of the growing aggregate, and (2) overwhelm the grain dispersive force resulting from charge repulsion or clast rebound after collision.

Figure 9. TEM photomicrographs from FIB sections located in Figure 7, from a natural CCA from FZB1136 (Figures 9a9d) and an experimental CCA from run 521 (Figures 9e-9h). Figures $9 \mathrm{~b}$ and $9 \mathrm{~h}$ are out of Figure 9a, but their relative position in CCA is located for a better understanding. (a) Contact between central clast and surrounding cortex. (b) Central clast of quartz. (c) Transition between the central clast (CC) and the surrounding cortex (C), showing the intermediate clayrich foliated layer with a white arrow (FL) and the cataclastic layer (CL). Inset shows electron diffraction patterns showing a diffusion ring pattern revealing a well-crystallized cataclastic zone. (d) Example of clasts, here feldspar and chlorite, surrounded by platy clay minerals in the cortex. Felds and $\mathrm{Mu}$ stand for feldspar and muscovite, respectively. (e) Contact between central clast and surrounding cortex. (f) Transition between the central clast of calcite (CC) and the surrounding cortex (C), showing the intermediate clay-rich foliated layer with a white arrow (FL) and the cataclastic layer (CL). (g) Nanometric clasts scattered within an amorphous clay material in the cortex. Inset shows electron diffraction patterns showing a diffusion ring pattern revealing locally the presence of amorphous material within the cortex. (h) Muscovite clast surrounded by platy clay minerals. 


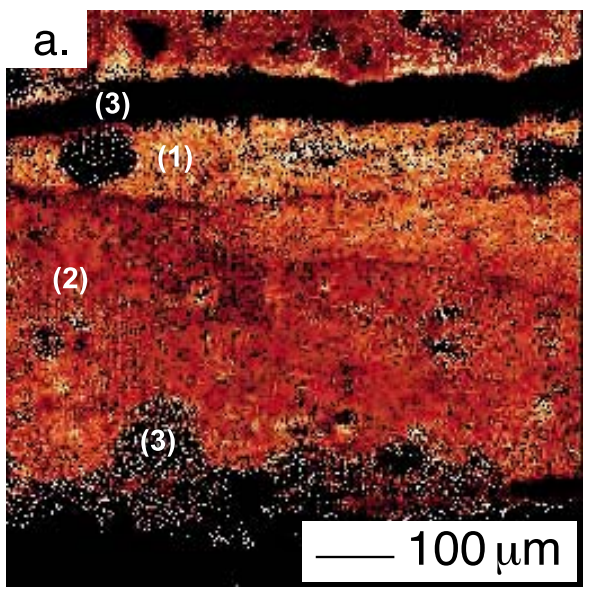

$\mathrm{OH} / \mathrm{H}_{2} \mathrm{O}(\%)$

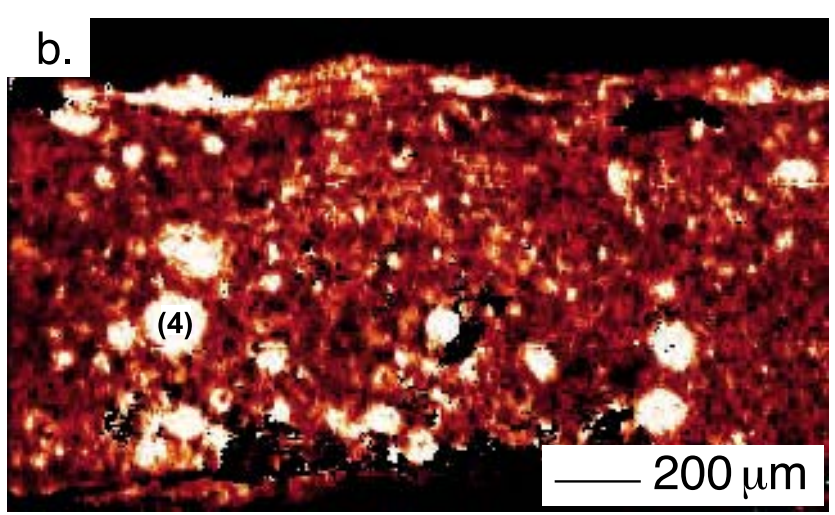

Figure 11. Infrared microscope images showing the location of low hydration areas (high ratio values) and high hydration areas of clays (low ratio value). (a) A postexperiment gouge sheared at $0.9 \mathrm{~m} \mathrm{~s}^{-1}$ in initially saturated conditions (521), located in Figure 1. From the top to the bottom, the ultrafine-grained foliated gouge zone (1), CCAbearing gouge layer (2), and epoxy (3) are shown. (b) A postexperiment gouge sheared at $1.3 \mathrm{~m} \mathrm{~s}^{-1}$ in initially nonsaturated conditions (728). Layer 4 corresponds to a CCA with a foliated gouge forming the central clast.

[29] Electrostatic Coulomb attraction is inversely proportional to the medium permittivity. Liquid-vapor phase transition of water (which implies a decrease of water density from 0.88 to 0.1 ) leads to a decrease of water permittivity by one order of magnitude (from 43.98 to $1.02 \varepsilon$ according to Chistyakov [2007]). Hence, the amount of released pore water vapor directly controls the permittivity of the gouge during shearing.

[30] The generation of electrostatic charges on solid particle surfaces can result from short-lived particle collision (i.e., fracto-emission process and triboelectric effect) [Gilbert et al., 1991] for the nucleus, and from natural highly negative electric charge lattice structure of smectites (due to the so-called electrical double layer at the surface of clay particles, see Tabbagh and Cosenza [2007]) for the cortex. The observed wide range of CCA sizes $(5-375 \mu \mathrm{m})$ with a larger amount of smaller CCAs is consistent with such assumption, considering that smaller particles have a higher $q / m$ ratio ( $q$ is the Coulomb charge and $m$ is the mass), which enhances the electrostatic forces, first due to their larger surface area to volume ratio and second due to the Paschen law (the decrease in air breakdown voltage with reduction in particle gap).

[31] This process of aggregation occurs during the slip weakening, when the gouge becomes fluidized [Boutareaud et al., 2008c]. However, the exact timing for apparition of CCAs remains debatable.

\subsection{Cortex Development}

[32] From an initial situation of a water vapor in a dynamic equilibrium with its nonvapor phases, the partial pressure of the water vapor can exceed the saturation vapor pressure, leading to the condensation of water. This would occur when the saturation vapor pressure becomes reduced (because of a reduction in the temperature) or when the partial pressure of water vapor increases (because of a reduction of the volume, for instance). At the steady-state friction, depending on initially saturated or nonsaturated conditions, the calculated exponential increase of temperature reaches a maximum value at the periphery comprised between 61 and $209^{\circ} \mathrm{C}$ for $0.09 \mathrm{~m} \mathrm{~s}^{-1}$ experiments at $0.6 \mathrm{MPa}$ (this study), between 375 and $420^{\circ} \mathrm{C}$ for $0.9 \mathrm{~m} \mathrm{~s}^{-1}$ experiments at $0.6 \mathrm{MPa}$ [Boutareaud, 2007], and between 355 and $420^{\circ} \mathrm{C}$ for $1.3 \mathrm{~m} \mathrm{~s}^{-1}$ experiments at $0.6 \mathrm{MPa}$ [Boutareaud et al., 2008a]. These results are inconsistent with the first proposition. However, a local drop of pressure in the vicinity of the rotating central clast appears to be compatible with the second alternative. This local drop of pressure might be explained by either (1) a "rotated pressure shadow" process showing the proximal pressure shadow rotating below the separatrix of the shear flow plane or (2) a local pressure gradient due to flow around the particles [Muite et al., 2004].

[33] The tendency of a surface to adsorb water depends on many factors including mineral composition, surface charge, surface roughness, the chemistry and $\mathrm{pH}$ of the pore water, and pressure-temperature conditions [Morrow et al., 2000; Jones et al., 2002].

[34] Clay particles (platelets) of the CCA cortex get aggregated in a spherical way. It results in an isotropic surface conductivity [Tabbagh and Cosenza, 2007] associated with a higher electrical conductivity perpendicular to the nucleus surface, which is proportional to the cation exchange capacity (CEC), i.e., the capacity of clay layers to exchange cations with surroundings [Ellis, 1987]. This is consistent with the observed random alternation of concentric micrometric porous and dense layers around the cortex.

[35] The adsorption of water is especially sensitive to the silanol density for the silica surface [Iler, 1979], which could be produced by crushing of quartz grains within pure water. This process induces a decrease in $\mathrm{pH}$ with increasing shearing duration [Saruwatari et al., 2004]. However, the very high $\mathrm{pH}(8.5-9.5)$ measured from the two Chelungpu borehole cores during and after drilling around the Chi-Chi PSZ [Chen et al., 2007] suggests that the $\mathrm{pH}$ should not play a major role in the adsorption of water for central quartz, but rather on the amount of smectite negatively charged [Kraepiel et al., 1998] and on their adhesion force to the surroundings [Plassard et al., 2005; Jouanna et al., 2008].

[36] The fully hydrophylic and electrically negative basal planes of smectites are known to attract and bind hydrated ions. However, the surprising absence of increase in the size 


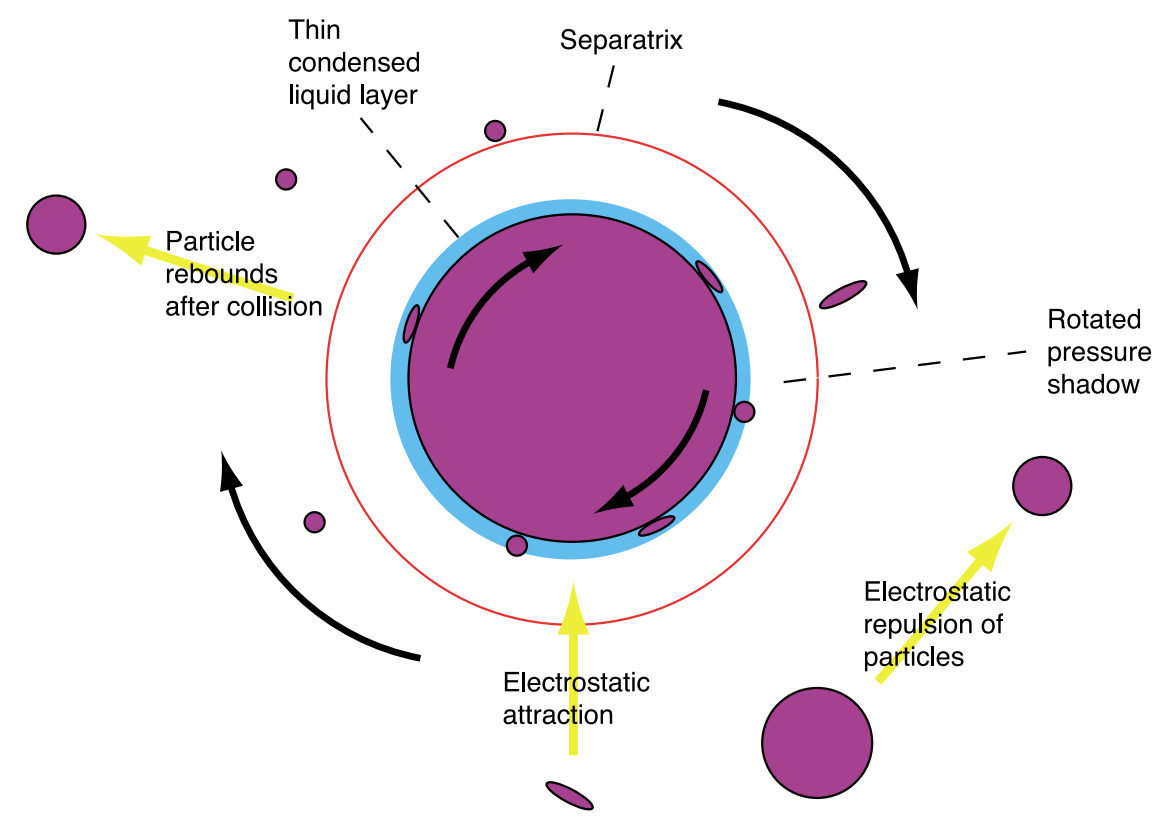

Figure 12. Schematic representation of aggregation processes for the formation and development of CCAs, taking place in a critical reactive liquid-vapor water medium (modified from Gilbert and Lane [1994]). Electrostatic forces attract long-ranged extremely fine mineral fragments from the surroundings, and capillary forces of the coated liquid (1) bind short-ranged attracted fragments to the central clast of the growing aggregate and (2) overwhelm the grain dispersive force resulting from charge repulsion or clast rebound after collision. The idealized separatrix surface lies between the spherical displacement path of the growing CCA, where a local drop of pressure occurs and open displacement paths farther away.

of CCA cortex from initially nonsaturated conditions to initially saturated conditions (Figure 5), usually provided by a consecutive increase of pull-off forces [Jones et al., 2002] and adsorbed water film layers [Ikari et al., 2007], suggests that gouge relative humidity should be lower than $25 \%$ [Jones et al., 2002], whatever the initially humid conditions. This assumption may well explain the observed high hydration state and the regular $15 \mu \mathrm{m}$ thick CCA cortex, whatever the initially humid conditions, slip velocity, or applied normal stress.

[37] Moreover, binding capillary forces between spheres of equal size are known to increase with increasing volume of the liquid bridge [Schubert, 1979]. These forces, which get stronger in the case of two spheres of different sizes (the liquid volume increases relative to the mass of the smaller sphere), are good candidates to explain the maximum $1 \mu \mathrm{m}$ size of mineral fragments contained within the cortex of the two types of CCAs. Hence, following the chemical potential definition of Tuller et al. [1999], adsorptive and capillary surface forces (which dominate at the dry and wet end of the degree of saturation, respectively) appear to have a common contribution to the formation of the CCAs, which implies that gouge humidity should be in the range of 5\%-25\% [Jones et al., 2002; Or and Tuller, 1999] during the formation of CCAs.

\section{Opening Issues}

[38] According the IR microscope results, the ultrafinegrained foliated gouge is more desiccated than that of the nonfoliated gouge. This observation suggests that the foli- ated gouge represents the heat generation zone caused by an extreme localization of the slip [Logan et al., 1979; Yund et al., 1990; Chester and Chester, 1998; Rice, 2006; Rockwell and Ben-Zion, 2007; Brantut et al., 2008]. Heat is then diffused across the entire fault gouge during shearing, leading to, first, a pore water liquid-vapor transition once the critical temperature is reached and, second, pressurization of the fault gouge (see section 4.1). The large fragments of ultrafine-grained foliated gouge forming the central clast of the largest CCAs in natural or experimental gouges (Figures 10 and 11) have three major implications. First, it indicates that the foliated gouge can be reworked in CCAs. This suggests that, for the foliated gouge to be pulled out, the simulated fault zone experienced granular flow process, i.e., a two-phase flow consisting of CCAs as particles and clay gouge matrix as interstitial fluid. Second, it means that, at least for some displacement during the slip weakening, the foliated gouge and CCAs are simultaneously formed in the fault zone. However, the exact timing of formation of CCAs during the slip weakening and its effect on the apparition of the narrow localized slip surface (i.e., the foliated gouge) remains uncertain [Boutareaud, 2007]. Third, the large fragments of ultrafine-grained foliated gouge forming the central clast of the largest CCAs do not correspond to an experimental artifact. This provides the evidence that this natural gouge from the Hole B has experienced a seismic slip.

[39] Detailed observations of the both natural and experimental gouges show the occurrence of an amorphous material in the cortex of CCAs. The exact mechanical origin of this material remains speculative, as no step experiments have so far been conducted. However, this material may 
originate from the gouge PSZ, as the result of local flash heating [Rice, 2006; Brantut et al., 2008] and intense grain size reduction [Yund et al., 1990].

[40] The aggregation process that has been reproduced from simulated seismic slip is enhanced by the critical reactive liquid-to-vapor pore water phase transition inducing gouge fluidization. This transition in the seismogenic zone does depend on the pressure-temperature conditions. Another subsequent potential parameter would be the amount of $\mathrm{CO}_{2}$ dissolved in pore water [Takenouchi and Kennedy, 1964]. However, the absence of any strong evidence of thermal decomposition products of carbonates from experimental gouges suggests that gas emission of $\mathrm{CO}_{2}$ [Han et al., 2007a, 2007b] did not occur during our experiments.

[41] Among the various thermally activated mechanisms proposed so far to account for the observed slip weakening, few of them are reasonably consistent with the fluidization of the sheared gouge. In the absence of any normal or inverse grading in the postexperiment gouges, and taking into account the low scale of the rotary shear experiment, acoustic dynamic fluidization [Melosh, 1996] can be ruled out. Conversely, thermal dehydration of clays, subsequent pore water phase change due to frictional heating, and consequent excess pore fluid pressure (considering that the fluid production rate is greater than the rate of fluid escape), is named thermal pressurization [Sibson, 1973; Wibberley and Shimamoto, 2005; Sulem et al., 2007]. This process represents a serious candidate to explain the observed reduction of the fault strength by Boutareaud et al. [2008c]. Finally, the natural CCAs reported in this paper, coming from the past-recognized 1999 earthquake Chi-Chi PSZ [Boullier et al., 2009], classify CCAs as new unequivocal textural evidence for shallow depth thermal pressurization and consequently for past seismic faulting.

[42] How deep the CCAs form in the upper crust highly depends on local pressure-temperature conditions, with respect to the water phase diagram [Wagner and Pruss, 2002]. However, as shown by Mizoguchi et al. [2007a], the amount of $\mathrm{CO}_{2}$ dissolved in pore gouge water would play a major role on the water liquid-vapor phase transition.

[43] Thermal dehydration of the fault gouge material [Mizoguchi et al., 2006; Hirose and Bystricky, 2007; Brantut et al., 2008] appears to be a serious candidate to explain clay interlayer-water removing and consecutive cortex structure collapse (i.e., radial compaction of the concentric dense layers) observed by EDX-SEM, with a higher relative atomic density of $\mathrm{Al}, \mathrm{Mg}$, and Fe element in the CCA cortex.

[44] The higher crystallinity of cortex for natural CCAs compared with experimental CCAs highly suggests that long-term in situ retrograde reactions of phyllosilicates due to hydrothermal reactions [Wintsch et al., 1995; Rutter et al., 1986; Vrolijk, 1990] have a critical impact on the preservation of CCAs contained within the short-lived PSZ: while the cristallinity of the experimental CCA has been "freezed" on thin sections, the cristallinity of the natural CCA has undergone retrograde reactions within the fault gouge, changing a material locally amorphous (i.e., in a metastable state) to stable phases, i.e., recrystallization. The efficiency of these processes, combined to subsequent overprinted embrittlement events, could highly explain the scarcity of natural examples reported so far.
[45] At high reactive hydrothermal conditions, depending on the prevailing fluid flow properties and permeability structure of the fault zone [Wibberley et al., 2008], after-slip period shows the occurrence of mechanical and chemical fluid-assisted fault healing with compaction [Sibson, 1989; Bos and Spiers, 2000, 2002; Nakatani and Scholz, 2004] and build-up of intergranular cohesion [Giger et al., 2008]. These processes increase grain contact area, which lead in turn to the development of cohesive bonds between adjacent particles, i.e., CCAs. This healing process may promote the static strength of the whole fault gouge in a short risetime, inhibiting by this way inter-seismic cataclastic granular flow (i.e., aseismic creeping behavior of the fault). This might have enough potential for first controlling the initial strength recovery for shallow depth seismogenic faults, which is the recurrence time for large earthquakes, and second modifying asperity structure on the PSZ, which can dramatically affect the subsequent coseismic fault slip [Sagy and Brodsky, 2009].

\section{Conclusions}

[46] CCAs resulting from friction experiments at seismic slip velocities exhibit similar characteristics to the natural CCAs recently observed from the PSZ of the seismogenic Chelungpu fault and recognized as the slipping zone of the Mw 7.6 1999 Chi-Chi earthquake.

[47] Similar to accretionary lapilli, CCA formation requires a common contribution of adsorptive and capillary surface forces, as the result of the natural highly negative electric charge lattice structure of smectites and a local pressure drop at constant humid conditions, respectively. However, a fundamental uncertainty remains on the possibility of other clay minerals, such as kaolinite, which frequently occurs in fault gouge, to allow such an aggregation process.

[48] Considering first the large-scale spatial heterogeneous distribution of ground acceleration along the Chelungpu fault trace that occurred during the Chi-Chi earthquake [Ma et al., 2003] and second that CCAs appear after experimental slip weakening representative to the typical risetime and breakdown stress drop of large earthquakes, based on fractal dimension, the volume ratio of CCAs could be a new indicator for thermal pressurization efficiency for a given fault segment.

[49] This work provides the evidence that CCAs can be seriously considered as new geological evidence for thermal pressurization and gouge fluidization at shallow depth, i.e., paleoseismic events along shallow crustal faults.

[50] Acknowledgments. The authors acknowledge two anonymous reviewers and an Associate Editor of the journal for their very constructive comments. The authors express their sincere thanks to Mai-Linh Doan, François Renard, and Thibault Candela for technical help on Matlab and helpful comments and discussions on fractal analyses on fault gouge particle size. Particular thanks to James Richard and Emilien Oliot for cathodoluminescence analyses. We thank Teng-fong Wong for TCDP thin section loan. The first author gratefully acknowledges Martine Buatier for her constructive comments that helped to improve this work. Michel Bouchon, Jean-Pierre Gratier, and Massimo Cocco are really thanked for encouragements and fruitful discussions on the background for this research. Muriel Andréani thanks Anne-Line Auzende for her assistance and fruitful discussions during transmission electron microscopy (TEM) observations of the FIB sections realized on a Jeol JEM-2100 at the IMPMC of Paris. Numerical simulations of temperature rise presented in this work have been realized with 
SETMP software on the cluster of Mathematics Laboratory of Besançon Dan-Gabriel Calugaru thanks the Franche-Comté Region for financial support. This work has been funded by NSC to Sheng-Rong Song (grants 93-2119-M-002 -028 and 94-2119-M-002-022), by ANR (Programme Catastrophes Telluriques et Tsunamis, ACTS Taiwan, ANR-06-CATT-001-01), and by International Laboratory CNRS-NSC France-Taiwan ADEPT.

\section{References}

Abe, S., and K. Mair (2005), Grain fracture in 3D numerical simulations of granular shear, Geophys. Res. Lett., 32, L05305, doi:10.1029/ 2004GL022123.

Anderson, J. L., R. H. Osborne, and D. F. Palmer (1983), Cataclastic rock of the San Gabriel fault: An expression of deformation at deeper crustal levels in the San Andreas fault zone, Tectonophysics, 98, 209-251, doi:10.1016/0040-1951(83)90296-2.

Beutner, E. C., and G. P. Gerbi (2005), Catastrophic emplacement of the Heart Mountain block slide, Wyoming and Montana, USA, Bull. Seismol. Soc. Am., 117, 724-735.

Bos, B., and C. J. Spiers (2000), Effect of phyllosilicates on fluid-assisted healing of gouge-bearing faults, Earth Planet. Sci. Lett., 184, 199-210, doi:10.1016/S0012-821X(00)00304-6.

Bos, B., and C. J. Spiers (2002), Fluid-assisted healing processes in gougebearing faults: Insights from experiments on a rock analogue system Pure Appl. Geophys., 159, 2537-2566, doi:10.1007/s00024-002-8747-2.

Boullier, A. M., Y. En-Chao, S. Boutareaud, S. R. Song, and C. H. Tsai (2009), Micro-scale anatomy of the 1999 Chi-Chi earthquake principal slip zone, Geochem. Geophys. Geosyst., 10, Q03016, doi:10.1029/ $2008 \mathrm{GC} 002252$

Boutareaud, S. (2007), Slip-weakening mechanisms at high slip-velocities Insights from analogue and numerical modellings, Ph.D. thesis, Univ. de Franche-Comté, Besançon, France.

Boutareaud, S., O. Fabbri, D. G. Calugaru, R. Han, and T. Shimamoto (2007), Clay-clast aggregates: A new textural evidence for seismic fault sliding?, Eos Trans. $A G U, 88(52)$, Fall Meet. Suppl., Abstract T33C-1492.

Boutareaud, S., A. M. Boullier, P. Beck, D. G. Calugaru, R. Han, and A. Tsutsumi (2008a), Clay-clast aggregates as new indicator of shallow crustal seismic slips, Geophys. Res. Abstr., 10, Abstract 04694, sref:16077962/gra/EGU08-A-04694.

Boutareaud, S., C. A. J. Wibberley, O. Fabbri, and T. Shimamoto (2008b), Permeability structure and co-seismic thermal pressurization on fault branches: Insights from the Usukidani Fault, Japan, in The Internal Structure of Fault Zones: Mechanical and Fluid Flow Properties, edited by C. A. J. Wibberley et al., Spec. Publ. Geol. Soc., 299, 341-361.

Boutareaud, S., D. G. Calugaru, R. Han, O. Fabbri, K. Mizoguchi, A. Tsutsumi, and T. Shimamoto (2008c), Clay-clast aggregates: A new structural evidence for seismic sliding?, Geophys. Res. Lett., 35 , L05302, doi:10.1029/2007GL032554.

Brantut, N., A. Schubnel, J. N. Rouzaud, F. Brunet, and T. Shimamoto (2008), High velocity frictional properties of a natural clay-bearing fault gouge and implications for earthquake mechanics, J. Geophys. Res., 113, B10401, doi:10.1029/2007JB005551.

Calugaru, D. G., J. M. Crolet, A. Chambaudet, C. I. Calugaru, and F. Jacob (2003), Inverse problems for flow and transport in the framework of seismic research, Cah. Phys., 14, 9-24.

Castro, J. M., P. Beck, H. Tuffen, A. R. L. Nichols, D. B. Dingwell, and M. C. Martin (2008), Timescales of spherulite crystallization in obsidian inferred from water concentration profiles, Am. Mineral., 93, 18161822, doi:10.2138/am.2008.2904

Chen, S. Y., S. R. Song, and C. H. Wang (2007), Chemical and isotopic characteristics of fluids from the Holes of Taiwan Chelungpu-fault Drilling Project, paper presented at Taiwan Geoscience Assembly, Longtan, Taiwan.

Chester, F. M., and J. S. Chester (1998), Ultracataclasite structure and friction processes of the Punchbowl fault, San Andreas system, California Tectonophysics, 295, 199-221, doi:10.1016/S0040-1951(98)00121-8.

Chistyakov, A. D. (2007), The permittivity of water and water vapor in saturation states, Russ. J. Phys. Chem. A, 81, 5-8.

Ellis, D. V. (1987), Well Logging for Earth Scientists, Elsevier, New York

Engelder, J. T. (1974), Cataclasis and the generation of fault gouge, Bull. Seismol. Soc. Am. 85, 1515-1522.

Giger, S. B., S. Cox, and E. Tenthorey (2008), Slip localization and fault weakening as a consequence of fault gouge strengthening-Insights from laboratory experiments, Earth Planet. Sci. Lett., 276, 73-84, doi:10.1016/j.epsl.2008.09.004

Gilbert, J. S., and S. J. Lane (1994), The origin of accretionary lapilli, Bull. Volcanol., 56, 398-411.

Gilbert, J. S., S. J. Lane, R. S. J. Sparks, and T. Koyaguchi (1991), Charge measurements on particle fallout from a volcanic plume, Nature, 349 598-600, doi:10.1038/349598a0.
Han, R., T. Shimamoto, J. Ando, and J. H. Ree (2007a), Seismic slip record in carbonate-bearing fault zones: An insight from high-velocity friction experiments on siderite gouge, Geology, 35, 1131-1134, doi:10.1130/ G24106A.1.

Han, R., T. Shimamoto, T. Hirose, J. H. Ree, and J. Ando (2007b), Ultralow friction of carbonate faults caused by thermal decomposition, Science, 316, 878-881, doi:10.1126/science. 1139763 .

Hirose, T., and M. Bystricky (2007), Extreme dynamic weakening of faults during dehydration by coseismic shear heating, Geophys. Res. Lett., 34 , L14311, doi:10.1029/2007GL030049.

Ikari, M. J., D. M. Saffer, and C. Marone (2007), Effect of hydration state on the frictional properties of montmorillonite-based fault gouge, J. Geophys. Res., 112, B06423, doi:10.1029/2006JB004748.

Iler, R. K. (1979), The Chemistry of Silica: Polymerization, Colloid and Surface Properties, and Biochemistry, Wiley-Interscience, New York.

Jefferson, I. F., B. Q. Jefferson, A. M. Assalay, C. D. F. Rogers, and I. F. Smalley (1997), Crushing of quartz sand to produce silt particles, Naturwissenschaften, 84, 148-149, doi:10.1007/s001140050366.

Jones, R., H. M. Pollock, J. A. S. Cleaver, and C. S. Hodges (2002), Adhesion force between glass and silicon surface in air studied by AFM: Effects of relative humidity, particle, size, roughness, and surface treatment, Langmuir, 18, 8045-8055, doi:10.1021/la0259196.

Jouanna, P., L. Pèdesseau, G. Pèpe, and D. Mainprice (2008), Mass and momentum interface equilibrium by molecular modeling. Simulating AFM adhesion between (120) gypsum faces in a saturated solution and consequences on gypsum cohesion, Cement Concr. Res., 38, 290-299, doi:10.1016/j.cemconres.2007.09.022.

Kano, Y., J. Mori, R. Fujio, H. Ito, T. Yanagidani, S. Nakao, and K.-F. Ma (2006), Heat signature on the Chelungpu fault associated with the 1999 Chi-Chi, Taiwan earthquake, Geophys. Res. Lett., 33, L14306, doi:10.1029/2006GL026733.

Keulen, N., R. Heilbronner, H. Stuenitz, A. M. Boullier, and H. Ito (2007), Grain size distributions of fault rocks: A comparison between experimentally and naturally deformed granitoids, J. Struct. Geol., 29, 1282-1300, doi:10.1016/j.jsg.2007.04.003.

Kraepiel, A. M. L., K. Keller, and F. M. M. Morel (1998), On the acid-base chemistry of permanently charged minerals, Environ. Sci. Technol., 32 2829-2838, doi:10.1021/es9802899.

Kuo, L. W., S. R. Song, and H. Y. Chen (2005), Characteristics of clay mineralogy in the fault zone of the TCDP and its implication, Eos Trans. $A G U, 86$, Fall Meet. Suppl., Abstract T43D-05.

Lachenbruch, A. H. (1980), Frictional heating, fluid pressure, and the resistance to fault motion, J. Geophys. Res., 85, 6097-6112, doi:10.1029/ JB085iB11p06097.

Logan, J. M., M. Friedman, N. Higgs, C. Dengo, and T. Shimamoto (1979), Experimental studies of simulated gouges and their application to studies of natural fault zones, U.S. Geol. Surv.Open File Rep., 1978, 305-343.

Ma, K. F., T. R. A. Song, S. J. Lee, and H. I. Wu (2000), Spatial slip distribution of the September 20, 1999, Chi-Chi, Taiwan, earthquake (Mw7.6)-Inverted from teleseismic data, Geophys. Res. Lett., 27, 3417-3420, doi:10.1029/2000GL011393.

Ma, K. F., E. E. Brodsky, J. Mori, C. Ji, T. R. A. Song, and H. Kanamori (2003), Evidence for fault lubrication during the 1999 Chi-Chi, Taiwan, earthquake (Mw7.6), Geophys. Res. Lett., 30(5), 1244, doi:10.1029/ 2002GL015380.

Mair, K., and C. Marone (1999), Friction of simulated fault gouge for a wide variety of velocities and normal stresses, J. Geophys. Res., 104, 28,899-28,914, doi:10.1029/1999JB900279.

Mair, K., and J. F. Hazzard (2007), Nature of stress accommodation in sheared granular material: Insights from 3D numerical modeling, Earth Planet. Sci. Lett., 259, 469-485, doi:10.1016/j.eps1.2007.05.006.

Mair, K., and C. Marone (2000), Shear heating in granular layers, Pure Appl. Geophys., 157, 1847-1866, doi:10.1007/PL00001064.

Mair, K., K. M. Frye, and C. Marone (2002), Influence of grain characteristics on the friction of granular shear zones, J. Geophys. Res., 107(B10), 2219, doi:10.1029/2001JB000516.

Mandl, G., L. N. J. de Jong, and A. Maltha (1977), Shear zones in granular material, Rock Mech., 9, 95-144, doi:10.1007/BF01237876.

Marone, C., and C. H. Scholz (1989), Particle-size distribution and microstructures within simulated fault gouge, J. Struct. Geol., 11, 799-814, doi:10.1016/0191-8141(89)90099-0.

Melosh, J. (1996), Dynamic weakening of faults by acoustic fluidization, Nature, 379, 601-606, doi:10.1038/379601a0

Mishima, T., T. Hirono, W. Soh, M. Ikehara, W. Lin, W. Tanikawa, E. C. Yeh, S. R. Song, and C. Wang (2006), Thermal history estimation of the Taiwan Chelungpu fault using rock magnetic methods, Geophys. Res. Lett., 33, L23311, doi:10.1029/2006GL028088.

Mizoguchi, K. (2004), High-velocity frictional behavior of Nojima fault gouge and its implications for seismogenic fault motion, Ph.D. thesis, Kyoto Univ., Kyoto, Japan. 
Mizoguchi, K., T. Hirose, T. Shimamoto, and E. Fukuyama (2006), The moisture-related weakening and strengthening of a fault activated at seismic slip rates, Geophys. Res. Lett., 33, L16319, doi:10.1029/ 2006GL026980.

Mizoguchi, K., M. Takahashi, K. Masuda, and E. Fukuyama (2007a), Fault strength drop due to phase transitions in the pore fluid, Geophys. Res. Lett., 34, L09313, doi:10.1029/2007GL029345.

Mizoguchi, K., T. Hirose, T. Shimamoto, and E. Fukuyama (2007b), Reconstruction of seismic faulting by high-velocity friction experiments: An example of the 1995 Kobe earthquake, Geophys. Res. Lett., 34, L01308, doi:10.1029/2006GL027931.

Mizoguchi, K., T. Hirose, T. Shimamoto, and E. Fukuyama (2008), Internal structure and permeability of the Nojima fault, southwest Japan, J. Struct. Geol., 30, 513-524, doi:10.1016/j.jsg.2007.12.002

Morrow, C. A., D. E. Moore, and D. A. Lockner (2000), The effect of mineral bond strength and adsorbed water on fault gouge frictional strength, Geophys. Res. Lett., 27, 815-818, doi:10.1029/1999GL008401.

Muite, B. K., M. L. Hunt, and G. G. Joseph (2004), The effects of a counter-current interstitial flow on a discharging hourglass, Phys. Fluids, 16, 3415-3425, doi:10.1063/1.1781158.

Nakatani, M., and C. H. Scholz (2004), Frictional healing of quartz gouge under hydrothermal conditions: 1. Experimental evidence for solution transfer healing mechanism, J. Geophys. Res., 109, B07201, doi:10.1029/2001JB001522.

Noda, H., and T. Shimamoto (2005), Thermal pressurization and slipweakening distance of a fault: An example of the Hanaore fault, southwest Japan, Bull. Seismol. Soc. Am., 95, 1224-1233, doi:10.1785 0120040089.

Ohtani, T., K. Fujimoto, H. Ito, H. Tanaka, N. Tomida, and T. Higuchi (2000), Fault rocks and past to recent fluid characteristics from the borehole survey of the Nojima fault rupture in the 1995 Kobe earthquake, southwest Japan, J. Geophys. Res., 105, 16,161-16,171, doi:10.1029/2000JB900086.

Or, D., and M. Tuller (1999), Liquid retention and interfacial area in variably saturated porous media: Upscaling from single-pore to samplescale model, Water Resour. Res., 35, 3591-3605, doi:10.1029/ 1999WR900262.

Plassard, C., E. Lesniewska, I. Pochard, and A. Nonat (2005), Nanoscale experimental investigation of particle interactions at the origin of the cohesion of cement, Langmuir, 21, 7263-7270, doi:10.1021/la050440+.

Rice, J. R. (2006), Heating and weakening of faults during earthquake slip, J. Geophys. Res., 111, B05311, doi:10.1029/2005JB004006.

Rockwell, T. K., and Y. Ben-Zion (2007), High localization of primary slip zones in large earthquakes from paleoseismic trenches: Observations and implications for earthquake physics, J. Geophys. Res., 112, B10304, doi:10.1029/2006JB004764.

Rutter, E. H., R. H. Maddock, S. H. Hall, and S. H. White (1986), Comparative microstructures of natural and experimentally produced claybearing fault gouges, Pure Appl. Geophys., 124, 3-30, doi:10.1007/ BF00875717.

Sagy, A., and E. E. Brodsky (2009), Geometric and rheological asperities in an exposed fault zone, J. Geophys. Res., 114, B02301, doi:10.1029/ 2008JB005701.

Sammis, C. G., and G. C. P. King (2007), Mechanical origin of power law scaling in fault zone Rock, Geophys. Res. Lett., 34, L04312, doi:10.1029/ 2006 GL028548.

Sammis, C. G., and Y. Ben-Zion (2008), Mechanics of grain-size reduction in fault zones, J. Geophys. Res., 113, B02306, doi:10.1029/ 2006JB004892.

Sammis, C. G., G. King, and R. Biegel (1987), The kinematics of gouge deformation, Pure Appl. Geophys., 125, 777-812, doi:10.1007/ BF00878033.

Saruwatari, K., J. Kameda, and H. Tanaka (2004), Generation of hydrogen ions and hydrogen gas in quartz-water crushing experiments: An example of chemical processes in active faults, Phys. Chem. Miner., 31, 176-182, doi:10.1007/s00269-004-0382-2.

Schubert, H. (1979), Grundlagen des agglomerierens, Chemieingenieurtechnik, 51, 266-277.

Schumacher, R., and H. U. Schmincke (1995), Models for the origin of accretionary lapilli, Bull. Volcanol., 56, 626-639.

Shimamoto, T., and A. Tsutsumi (1994), A new rotary-shear high-velocity frictional testing machine: Its basic design and scope of research (in Japanese with English abstract), Struct. Geol., 39, 65-78.

Sibson, R. H. (1973), Interactions between temperature and pore-fluid pressure during earthquake faulting and a mechanism for partial or total stress relief, Nature Phys. Sci., 243, 66-68.
Sibson, R. H. (1989), Earthquake faulting as a structural process, J. Struct Geol., 11, 1-14, doi:10.1016/0191-8141(89)90032-1.

Sibson, R. H. (2003), Thickness of the seismic slip zone, Bull. Seismol. Soc. Am., 93, 1169-1178, doi:10.1785/0120020061.

Solum, J. G., S. H. Hickman, D. A. Lockner, D. E. Moore, B. A. van der Pluijm, A. M. Schleicher, and J. P. Evans (2006), Mineralogical characterization of protolith and fault rocks from the SAFOD main hole, Geophys. Res. Lett., 33, L21314, doi:10.1029/2006GL027285.

Sulem, J., P. Lazar, and I. Vardoulakis (2007), Thermo-poro-mechanical properties of clayey gouge and application to rapid fault shearing, Int J. Numer. Anal. Methods Geomech., 31, 523-540, doi:10.1002/nag.584.

Tabbagh, A., and P. Cosenza (2007), Effect of microstructure on the electrical conductivity of clay-rich systems, Phys. Chem. Earth, 32 $154-160$

Takenouchi, S., and G. C. Kennedy (1964), Binary system $\mathrm{H}_{2} \mathrm{O}-\mathrm{CO}_{2}$ at high temperatures and pressures, Am. J. Sci., 262, 1055-1074.

Tanaka, H., W. C. Chen, C. Y. Wang, K. F. Ma, N. Urata, J. Mori, and M. Ando (2006), Frictional heat from faulting of the 1999 Chi-Chi, Taiwan earthquake, Geophys. Res. Lett., 33, L16316, doi:10.1029/ 2006GL026673.

Tuller, M., D. Or, and L. M. Dudley (1999), Adsorption and capillary condensation in porous media: Liquid retention and interfacial configurations in angular pores, Water Resour. Res., 35, 1949-1964, doi:10.1029/ 1999WR900098.

Vrolijk, P. (1990), On the mechanical role of smectite in subduction zones, Geology, 18, 703-707, doi:10.1130/0091-7613(1990)018<0703 OTMROS $>2.3 . \mathrm{CO} ; 2$

Vrolijk, P., and B. A. van der Pluijm (1999), Clay gouge, J. Struct. Geol., 21, 1039-1048, doi:10.1016/S0191-8141(99)00103-0.

Wagner, W., and A. Pruss (2002), The IAPWS formulation 1995 for the thermodynamic properties of ordinary water substance for general and scientific use, J. Phys. Chem. Ref. Data, 31, 387-535, doi:10.1063/ 1.1461829

Wang, C. Y., N. H. Mao, and F. T. Wu (1980), Mechanical properties of clays at high pressures, J. Geophys. Res., 85, 1462-1468, doi:10.1029/ JB085iB03p01462.

Warr, L. N., and S. J. Cox (2001), Clay mineral transformations and weakening mechanisms along the Alpine Fault, New Zealand, in The Nature and Significance of Fault Zone Weakening, edited by R. E. Holdsworth et al., Spec. Publ. Geol. Soc., 186, 85-101.

Wibberley, C. A. J., and T. Shimamoto (2005), Earthquake slip weakening and asperities explained by thermal pressurization, Nature, 436, 689692, doi:10.1038/nature03901.

Wibberley, C. A. J., W. Kurz, J. Imber, R. E. Holdsworth, and C. Collettini (2008), The Internal Structure of Fault Zones: Implications for Mechanical and Fluid-Flow Properties, Geol. Soc. Spec. Publ., 299, 367 pp.

Wintsch, R. P., R. Christoffersen, and A. K. Kronenberg (1995), Fluid-rock reaction weakening of fault zones, J. Geophys. Res., 100, 13,02113,032, doi:10.1029/94JB02622.

$\mathrm{Yu}, \mathrm{S}$. B., et al. (2001), Preseismic deformation and coseismic displacements associated with the 1999 Chi-Chi, Taiwan, earthquake, Bull. Seismol. Soc. Am., 91, 995-1012, doi:10.1785/0120000722.

Yund, R. A., M. L. Blanpied, T. E. Tullis, and J. D. Weeks (1990), Amorphous material in high strain experimental fault gouges, J. Geophys. Res. 95, 15,589-15,602, doi:10.1029/JB095iB10p15589.

M. Andréani, Laboratoire des Sciences de la Terre, UMR 5570, INSU, Université Claude Bernard, Lyon I, Ecole Normale Supérieure de Lyon, CNRS, ENS Lyon, Bat. Géode - R6, 2 rue Raphael Dubois, F-69622 Villeurbanne CEDEX, France.

P. Beck, Laboratoire de Planétologie de Grenoble, Université Joseph Fourier, BP 53, F-38041 Grenoble, France.

A.-M. Boullier, Laboratoire de Géophysique Interne et Tectonophysique, CNRS, Université Joseph Fourier, Maison des Géosciences, BP 53, F-38041 Grenoble CEDEX 9, France.

S. Boutareaud, Geologisches Institut, ETH-Zentrum, CH-8092 Zurich, Switzerland. (sebastien.boutareaud@erdw.ethz.ch)

D.-G. Calugaru, Laboratoire de Mathématiques, Université de FrancheComté, F-25030, Besançon, France.

T. Shimamoto, Department of Earth and Planetary Systems Science, Hiroshima University, Higashi-Hiroshima, Hiroshima, 739-8526, Japan.

S.-R. Song, Department of Geosciences, National Taiwan University, 1 Roosevelt Rd. Section 4, Taipei 106, Taiwan. 